\title{
Socio-Health Determinants of Occurrence of Postpartum Hemorrhage Among Women of Reproductive Age 15-49 Years - Kenya
}

\author{
${ }^{1}$ Adel W. Ottoman, ${ }^{2}$ Dr Charles Angira, ${ }^{3}$ Dr Jane Owenga, ${ }^{4}$ Dr Japheth Ogendi \\ P.O Box 52 Homa Bay, Kenya \\ 1,2,3 Jaramogi Oginga Odinga University of Science and Technology
}

\section{Abstract \\ SOCIO-HEALTH DETERMINANTS OF OCCURRENCE OF POSTPARTUM HEMORRHAGE}

Postpartum hemorrhage is the blood loss of $500 \mathrm{ml}$ or more within 24 hours after birth. It is the number one direct cause of maternal mortality Worldwide and constitutes $73 \%$ of all the obstetric hemorrhage globally. In Low-income Countries such as Sub-Saharan Africa bears the greatest burden of postpartum hemorrhage. Thirty-four percent of maternal deaths occurring in Kenya are due to postpartum hemorrhage. In Homa Bay County, postpartum hemorrhage is the leading cause of maternal mortality contributing $38 \%$ of all maternal deaths despite several strategies by the ministry of health to reduce occurrence. Previous studies attribute this to poor provision and utilization of essential health services. The possible contextual contribution of health system management on occurrence of postpartum hemorrhage has not been explored in the County. The objective of this study was to establish the socio-health determinants of occurrence of postpartum hemorrhage among women of reproductive age 15-49 years in Homa Bay County. The specific objectives were: to identify the socio-demographic determinants of occurrence of postpartum hemorrhage among women of reproductive age; and to determine the personal health determinants of occurrence of postpartum hemorrhage among women of reproductive age. This was a cross-sectional study design in which qualitative and quantitative methods were used. The target population was postnatal women who delivered at the level four public hospitals in Homa Bay County. The sample size was 400 postnatal women. Quantitative data was collected using a structured for socio-demographics determinants, and personal health determinants. Qualitative data was collected using Key Informant Interview guides administered to the eight Sub County Medical Officers of Health and the one County Gynecologist and was recorded. This data was managed thematically while quantitative data was cleaned manually and electronically. The Statistical Package for Social Sciences (SPSS) was used for data processing and analysis. The first stage was processing and analysis involving computation of frequencies and percentages and generation of tables followed by the binary logistic regression for bivariate variables to determine the relationship, adjusted Odds Ratio to determine the degree of significance at a confidence interval of $95 \%$ and P-value for each category of the variables. Thematic approach guided the analysis of qualitative data. Socio-health determinants were found statistically significant with multiple logistic regression with $\left(\chi^{2}\right.$ =62.08; P-Value=0.01). The findings had constructing and reviewing programs for women of reproductive age focusing on start of ANC at $1^{\text {st }}$ trimester, age at first both, and the general socio-demographic characteristics through strengthening of community health strategy to improve social and personal health characteristics.

\subsection{Introduction}

Postpartum hemorrhage (PPH) is the loss of blood more than $500 \mathrm{ml}$ following vaginal delivery or more than $1000 \mathrm{ml}$ following caesarean section by a postnatal woman within 42 days of termination of pregnancy (Zahran et al. 2016). However, World Health Organization, 2017 defines it as a blood loss of $500 \mathrm{ml}$ or more within 24 hours after birth. In anemic postnatal mothers, even less than $500 \mathrm{ml}$ in vaginal delivery or less than $1000 \mathrm{ml}$ in caesarean delivery would cause complications. It is categorized as either primary or secondary. Primary postpartum hemorrhage is the most common form of obstetric hemorrhage. The traditional definition of primary $\mathrm{PPH}$ is the loss of $500 \mathrm{ml}$ or more of blood from the genital tract within 24 
hours of the birth of a baby. Other researchers define Primary postpartum hemorrhage (PPH) as loss of blood estimated to be $>500 \mathrm{ml}$, from the genital tract, within 24 hours of delivery (the most common obstetric hemorrhage) and classify it as either minor PPH: blood loss up to $1000 \mathrm{ml}$ and major PPH as any estimated blood loss over $1000 \mathrm{ml}$. Major postpartum hemorrhage can either be moderate (1000-2000ml) or severe (more than 2000ml). Secondary PPH is defined as abnormal or excessive bleeding from the birth canal between 24 hours and 12 weeks postnatal. However, agreement on the criteria for the inclusion of an individual as a case of maternal hemorrhage has not been easily achieved. There are problems in actual measuring of blood loss during delivery and in the postpartum period. According to Prasertcharoensuk et al, 2003, physicians tend to underestimate the quantity of blood loss. The sequelae considered for postpartum hemorrhage in Global Burden of Diseases (GBD) 1990 were Sheehan's syndrome and severe postpartum anemia. Sheehan's syndrome consists of pituitary necrosis following hemorrhagic shock during delivery. The symptoms comprise chronic weakness, premature old age, amenorrhea and mental changes, including apathy and confusion. These symptoms may never be severe and may be delayed for several years.

The main causes of postpartum hemorrhage have been linked to the three delays, lack of proper equipment, distance, bad roads, indecision, professional negligence, lack of blood and blood products, age, parity, literacy, poverty, abortion, history of stillbirths, anemia, and infections (Hailu \& Kebede, 1994). Lack of simple, affordable and basic frameworks of essential health services that target postpartum hemorrhage cases greatly contribute to the reduction of the postpartum hemorrhage (WHO, 2015). Lack of blood cause delay by providers and is an unavoidable factor in most facility-based death where $44 \%$ of postpartum hemorrhage cases occur due to third delay (Felarmine et al., 2016). The causes of postpartum hemorrhage therefore are summarized as the four " $\mathrm{T}$ " factors of postpartum hemorrhage: Tone, Tissue, Trauma, and Thrombosis.

Uterine atony occurs in about 80 percent of cases. Atony may be related to over distension of the uterus, infection, placental abnormalities, or bladder distension. Though the majority of women who develop postpartum hemorrhage (PPH) have no identifiable risk factors, clinical factors associated with uterine atony, such as multiple gestations, polyhydramnios, high parity, and prolonged labour, may lead to a higher index of suspicion. Other causes of postpartum hemorrhage (PPH) include retained placenta or clots (Tissue), lacerations, uterine rupture or inversion (Trauma), an inherited or acquired coagulation abnormalities (Thrombosis) (Health \& Services, 2016). The essential routine postpartum hemorrhage prevention and management care services include promotion of the antenatal clinic (ANC) visit during pregnancy for anemia monitoring and the venereal infections; promotion of health education on communitybased maternal services such as delivery plan where transport to a health facility is arranged; quality maternal health care at the facility especially Active Management Third Stage of Labor (AMTSL) and proper emergency preparedness (Duke et al., 2016).

Majority of the deaths are as a result of conditions that can be prevented using affordable, feasible and sustainable interventions that can also be applied even in the poorest settings. The measures have been categorized into three levels: First delay in deciding to seek appropriate care due to socio-cultural barriers, failure to recognize danger signs, failure to perceive severity of illness, and cost considerations: Second delay in reaching an appropriate health care facility due to long distance to a facility, poor condition of roads, lack of transportation and cost considerations and third delay in receiving adequate emergency care at the facility due to shortage of staff, supplies, and basic equipment; unskilled personnel, user fees among others. Inadequate clinical expertise (Smith et al., 2014).

\subsection{Background of the study}

Postpartum hemorrhage is a worldwide problem (Maswime \& Buchmann, 2017). Postpartum hemorrhage $(\mathrm{PPH})$ is the number one direct cause of maternal mortality and morbidity (WHO, 2014). Globally, 13 million postnatal women experience postpartum hemorrhage, 1.56 million who survive develop severe anemia and 500,000 (34\%) (WHO \& Unicef, 2012). In Chinese provinces, postpartum hemorrhage accounts for nearly $50 \%$ of all maternal deaths (Kwast, 1991). Postpartum hemorrhage is one of the most serious challenges faced by the international community and that inequality still exists within and between countries in relation to progress in reducing postpartum hemorrhage maternal mortalities and morbidities (Weidert $e t$ $a l$,. 2013). Low-income countries contribute $99 \%$ of all the maternal deaths caused by postpartum 
hemorrhage (Mousa et al,. 2014). Eighty-eight percent of maternal deaths due to postpartum hemorrhage occur within 4 hours of delivery (Kane, 1992). Co-morbidities of postpartum hemorrhage include hypertension pregnancy disorders, unsafe abortions, septic infections, obstructed labour, cervical cancer, breast cancer, diabetes, AIDS, road carnage, anaemia, and other causes. In Kenya, postpartum hemorrhage accounts for $34 \%$ of all maternal deaths (CGHBC report,2017).

Maternal deaths are noted to occur more in the rural areas, in poor households or to mothers with no basic awareness of postpartum hemorrhage (WHO, 2015). Many efforts are targeting reducing maternal mortality in Kenya with the main focus on postpartum hemorrhage as the main direct cause of morbidity and mortality among expectant mothers.

In Homa Bay County, postpartum hemorrhage is the leading cause of maternal mortality. Maternal mortality in Homa Bay County is twice the national rate: 583/100,000 versus 362/100,000 live births (KDHS, 2015). Postpartum hemorrhage contributes 38\% of all the maternal deaths in Homa Bay County (CGHB Report, 2018) which a $10 \%$ increase from 2015. The effect of postpartum hemorrhage in Homa Bay County is high (Felarmine et al., 2016). HIV/AIDS causes immunodeficiency hence severe underlying infections, which exacerbates postpartum hemorrhage. Homa Bay County is also within the malaria-endemic region $(58,820$ per 100,000 population), which causes a lot of anemia (PIMA, 2017). High poverty level in this county also worsens the situation. According to Economic Survey 2014, Homa Bay County poverty rate was 48.4 percent against the national 36.1 percent (KNBS, 2016).

The main causes of postpartum hemorrhage have been linked to the three delays. First delay are caused by low status, lack of awareness of obstetric complications, nearest healthcare facility is more than $1 \mathrm{~km}$ away, uneventful previous home delivery, the family has insufficient money, poor experience of previous health care received at a healthcare facility, perceived poor quality of care at a healthcare facility, avoiding admission and long stay at a healthcare facility (Beck \& Grande, 2010). The second delay is caused by inaccessibility of health facility for more than one hour due to long travel time from home to a health facility, cost of transportation, poor road condition or terrain, and visited a traditional healer or traditional birth attendant first. The third delay is caused by long waiting time before treatment is received; more than $30 \mathrm{~min}$ from the time of arrival to time of being assessed or receiving treatment, shortage of equipment and supplies, wrong assessment of risk, wrong diagnosis, wrong treatment, shortage of healthcare providers, lack of competence or skills among the available healthcare providers, healthcare provider unavailable, inadequate referral system, ambulances not available, no fuel, breakdown and use of public transport, and lack of treatment guidelines e.g. Pre-eclampsia, postpartum hemorrhage, manual removal of placenta.

Other causes of postpartum hemorrhage include lack of proper equipment, distance, bad roads, indecision, professional negligence, lack of blood and blood products, age, parity, literacy, poverty, abortion, history of stillbirths, anemia and infections (Opon, 2017).

\subsection{Problem statement}

Maternal Postpartum hemorrhage is the leading direct cause of maternal mortality in Homa-Bay County, contributing $38 \%$ of all maternal deaths ( $\mathrm{CGH}, 2018)$. Maternal mortality in Homa Bay County due postpartum hemorrhage moved from 34\% to 38\% from 2015 to 2017 (DHIS, 2017). In Homa Bay County, maternal mortality is about double the national rate of 583/100,000 compared to 362/100,000 National live births (Agina et al., 2016). Postpartum hemorrhage remains the leading cause of maternal morbidity and mortality despite interventions such as; training of health care workers on basic obstetric care and comprehensive obstetric care, rolling out of universal health coverage, free maternal care, increased health financing through NHIF (Gok, 2011). Integration of health services for the postnatal mothers at community and the health facility levels is also an intervention that is intensified (CHS 2011). Another intervention that is identified is increasing the number of human resource for health, buying necessary equipment, capacity building and training staff on management postpartum hemorrhage (HSSP 2017/2022).

\subsection{Objectives}

This study focused on the following one broad objective and three specific objectives for the study to realize its main aim. 


\subsubsection{Broad Objective}

To establish the socio-health determinants of occurrence of postpartum hemorrhage among women of reproductive age 15-49 years in Homa-Bay County.

\subsubsection{Specific Objectives}

1. To identify socio-demographic determinants of occurrence of postpartum hemorrhage among women of reproductive age 15-49 years in Homa-Bay County.

2. To determine the personal health determinants of occurrence of postpartum hemorrhage among women of reproductive age 15-49 years in Homa-Bay County.

\subsection{Research Questions}

This study focused on the following one broad Research Question and three specific Research Questions for the study to realize its main Purpose.

\subsubsection{Broad Research Question}

What were the socio-health determinants of occurrence of postpartum hemorrhage among women of reproductive age 15-49 years in Homa-Bay County?

\subsubsection{Specific Research Questions}

1. What were the socio-demographic determinants of occurrence of postpartum hemorrhage among women of reproductive age 15-49 years in Homa-Bay County?

2. What were the personal health determinants of occurrence of postpartum hemorrhage among women of reproductive age 15-49 years in Homa-Bay County.?

\subsection{Justification of the study}

Postpartum hemorrhage is quite an invisible killer and huge menace for the lives of women and families in Homa Bay County common anemia cases, serious underlying conditions and poverty rate (50.6\%) due to high prevalence of malaria (27\%) and HIV/AIDS (18.6\%) (CGHB, 2020). It is a big worry to the health systems and the community as the maternal morbidity and mortality due to postpartum hemorrhage remain high. This study therefore envisions to establish the influences of health system management and give appropriate recommendations informing corrective measures to curb postpartum hemorrhage.

\subsection{Significance of the study}

Implementation of the recommendations herein will ensure reduced cases of postpartum hemorrhage among postnatal women due to enhanced community strategy activities focusing on social behavior change and communication, improved personal health characteristics, and strengthened health systems in managing occurrence of postpartum hemorrhage.

\subsection{Scope/delimitation of the study}

This study was conducted in Homa Bay County from November to December 30, 2019. Data was collected from the 12 level 4 public hospitals in all the 8 Sub Counties in the County. This study adopted the crosssectional study design with both quantitative and qualitative methods. The respondents were the sampled 400 postnatal women, maternity in-charges and Matrons of the hospitals, and the eight Sub County Medical Officers of Health. Data was collected through structured questionnaire and semi-structured questionnaire. Processing and analysis involved computation of frequencies and percentages, logistic regression, adjusted Odds Ratio, P-value, and multivariate logistic regression. Thematic approach was used for analyzing qualitative data.

\subsection{Limitations of the study}

The weather was too cold, and rainy making travelling to the 12 level 4 public hospitals very challenging. Some women had to be given long hours for them to be enrolled to fill the questions because of long hours of laboring. The health care workers strike occasionally interfered with the flow of patients however, this we went through and got the required number. 


\subsection{Study assumptions}

The study assumed that women would give birth at the 12 level 4 public hospitals and that postpartum hemorrhage would occur. It was also assumed that all the devices used for data collection and processing would work optimally. The study also assumed that there would be significant socio-demographics characteristics determined occurrence of postpartum hemorrhage, and that personal health determined occurrence of postpartum hemorrhage. The study, therefore, assumed that postnatal women, care providers were going to give adequate, reliable and useful information in the study.

\section{Literature Review}

\subsection{Introduction}

This chapter two presents the literature reviewed with reference to the management of occurrence of postpartum hemorrhage. This literature review critically examined and discussed the research that were done and documented on postpartum hemorrhage and related documents. Previous research and documents would be located, analyzed, synthesized and interpreted from sources such as periodicals, books, extracts, web pages and comments related to the topic of this study.

It begins with literature on socio-demographic determinants of occurrence of postpartum hemorrhage, and personal health determinants of occurrence of postpartum hemorrhage. The chapter ends with the conceptual framework to guide the conduct of this study.

\subsection{Socio-demographic determinants of occurrence of postpartum hemorrhage}

These to a great extent notwithstanding the state of the facility-based health systems, determine the occurrence of postpartum hemorrhage. They are known as the "too" factors: too young, too old, too many, too frequent and too sick. Place of residence, household wealth, education, parity, and age at birth strongly influence the occurrence of postpartum hemorrhage (Ochako et al., 2011).

Women who have attained higher educational qualifications tend to have more understanding of the importance of preventive and management measures. Educated women have higher autonomy to make decisions on the quality of health care they receive and educated young women are better users of skilled professional assistance that ultimately help prevent and manage postpartum hemorrhage (Ochako et al., 2011). Poorly educated women give birth too early, too many, and too frequently which are factors associated with occurrence of postpartum hemorrhage (Campbell, 1992).

Majority of young women in Kenya delay seeking skilled professional care which exposes them to the risk of experiencing postpartum hemorrhage due to low social status and unplanned pregnancies (Ochako et al., 2011). Too young (below 18 years old) expectant women experience bleeding complications during birth and are at higher risk of postpartum hemorrhage maternal mortality. Women who give birth in their late years of reproductive ages such as above 35 years tend to develop hemorrhage complications. The risk of postpartum hemorrhage maternal mortality is highest for adolescent girls under 15 years old. Complications in pregnancy and childbirth are the leading cause of death among adolescent girls in developing countries (WHO, 2014).

Pregnancies within less than 2 years apart cause complications. The shorter the gap between the pregnancies the more the chances that the woman's blood level shall have not stabilized hence any little blood loss may lead to anemia. On the other hand, the higher parity women are less likely to use skilled professional assistance at delivery, as they feel experienced and knowledgeable from previous birth experiences (Ochako et al., 2011).

Too sick (pregnancies contraindicated). Underlying diseases may worsen the condition when post hemorrhage occurs. Maternal death without doubts is associated with considerable grief and depression (Stein et al., 2003). 


\subsection{Personal health determinants of occurrence of postpartum hemorrhage}

This is composed of health seeking behavior, community factors and history of health. Care during pregnancy and place of delivery define the decision to seek health care services by patients. Qualitative data confirm increased recognition of the importance of professional antenatal and delivery care, as reported in the 2006 NDHS and in a recent Knowledge Attitude and Practice Study. The major finding is an association between early timing of the first ANC visit and use of skilled professionals at delivery. There was strong evidence that more women are conscious about their well-being during pregnancy and are taking better care of their health, for example consuming nutritious foods such as green vegetables, fish, meat, eggs, and fruit during pregnancy and not doing heavy work. However, some studies indicated that pregnant mothers are obliged to carry out heavy work and not getting sufficient good food. Qualitative evidence also indicates traditional practices and belief that pregnant women should not go out of the house after labor begins and women and those pregnant women should not cross a river, as this carried a risk of "devil spirits" taking over their bodies. Hence some women were not able to go for antenatal check-ups (Baqui et al., 2009).

There is a broad consensus that most women (and their families) still preferred a home delivery as it was traditional practice in their community. Women are being assisted by Traditional Birth Attendants (DHIS 2016) because TBAs' had attended many deliveries and were readily available in their neighborhood, and said they would seek care from health facilities only if there were complications that the TBA or primary care could not handle. Reasons for opting for home delivery include perception of safety at home, convenience, and shyness, availability of clothes and food, and lower cost. Lack of electricity and heating in the facility was also a factor.

Around three-quarters of the world's absolute poor, live in middle-income countries (Senkubuge et al., 2014). The cost of care is a significant barrier to quality health care. In Kenya, young women from rich households are more likely to use skilled professional assistance at delivery (Ochako et al., 2011) however majority of young women in Kenya delay seeking skilled professional care which exposes them to the risk of postpartum hemorrhage. This could be due to their low social status and unplanned pregnancies (Ochako et al., 2011). Women deliver at home without skilled assistance because of cost (Cost of care takers, transport and treatment cost make expectant women more reluctant to visit higher-level referral centers (Muruka et al., 2017).

Shame is a major reason why women do not go to a health facility, especially if the service provider was male. Women may return without receiving a check-up or may not go to a health facility at all if there are only male providers (Suvedi et al., 2009).

Inadequate numbers of staff and lack of physical resources and facilities, lead to service users waiting long periods, some services not being available and provision of services only at certain hours or on some days, all of which discourage women from seeking care (Kaczyńska et al., 2016). Health care workers are sometimes rude and uncaring. Women reported both positive and negative experiences with service providers. Some, especially those who had been treated for complications, said that, compared with the past, the behavior of health facility staff had improved, and they provided emotional support and were helpful and friendly. Others said that negative attitudes and behavior of health care staff still discourage women from utilizing government maternal health care services (Homa Bay County Reports, 2016). A few women with complications also indicate that service providers were rude and unfriendly, scolding them, not showing concern when they are in pain, making them wait and giving priority based on their liking and language bias.

Beliefs such as pregnant women are not supposed to cross rivers. It's a taboo to remove newborn out of the house within the first 4 days after birth. Such traditions make decisions to seek care delayed. Research shows that traditional beliefs cause up to $17 \%$ of community delays. History of health of the postnatal women has influence on the occurrence of postpartum hemorrhage. The past conditions of the postnatal woman on experiences of postpartum hemorrhage, gestation period, gravidity and trimester started antenatal clinic is very important and influence postpartum hemorrhage. Night complications and deliveries cause up to $18 \%$ of the delays. Women not being able or not wanting to seek care alone or needing permission to seek 
care also contribute to delays (Borghi, Ensor, Neupane, \& Tiwari, 2006) because they are disadvantaged in terms of decision making. For example, some have to consult their husbands and mothers-in-law before seeking maternal health care (Ochako et al., 2011).

A large percentage of young pregnant women do not seek ANC during their first trimester as is recommended by the WHO, in fact, a considerably high proportion of young women use TBAs as opposed to using skilled professionals (Ochako et al., 2011). Mother-in-law makes the decision to seek institutional delivery (Darcy et al., 2013).

\subsection{The Health Belief Theory}

Social determinants of health (SDH) are the non-medical factors that influence health outcomes. They are the conditions in which people are born, grow, work, live, and age, and the wider set of forces and systems shaping the conditions of daily life (WHO, 2021). The Health Belief Model is a theoretical model that can be used to guide health promotion and disease prevention programs. It helps to understand the failure of people to adopt disease prevention strategies or screening tests for the early detection of disease. is used to explain and predict individual changes in health behaviours. WHO's 1948 Constitution clearly acknowledges the impact of social and political conditions on health. and the HBM suggests that a person's belief in a personal threat of an illness or disease together with a person's belief in the effectiveness of the recommended health behavior or action will predict the likelihood the person will adopt the behaviour. Ultimately, an individual's course of action often depends on the person's perceptions of the benefits and barriers related to health behavior.

As one of the most widely applied theories of health behavior (Glanz \& Bishop, 2010), the Health Belief Model (HBM) posits that six constructs predict health behavior: risk susceptibility, risk severity, benefits to action, barriers to action, self-efficacy, and cues to action (Becker, 1974; Champion \& Skinner, 2008; Rosenstock, 1974). It was formulated to model the adoption of preventive health behaviors.

"Health care is an important determinant of health. Lifestyles are important determinants of health. But... it is factors in the social environment that determine access to health services and influence lifestyle choices in the first place." WHO Director-General Dr Margaret Chan.

\subsubsection{Theoretical concept of Senkubuge}

The seven components of the framework represent the operational levels required to ensure coverage (implementation and access) of postpartum hemorrhage interventions. The broader environment and context represent environmental and contextual elements that affect postpartum hemorrhage and health systems including governance, political stability, and accountability, economic growth, demographic trends, disease profile, infrastructure relating to water and sanitation, transportation, communication, and information technology (UNICEF, 2011). National Inter-sectoral policy and strategy components include government strategies for economic growth and poverty reduction, linkages with the private sector, disaster preparedness and enabling inter-sectoral environment (UNICEF, 2011). Health sector leadership, policy, and regulation represent the role of the ministry of health on policy direction relating to regulation, primary health care, financing, human resources, drugs and supplies (UNICEF, 2011). 


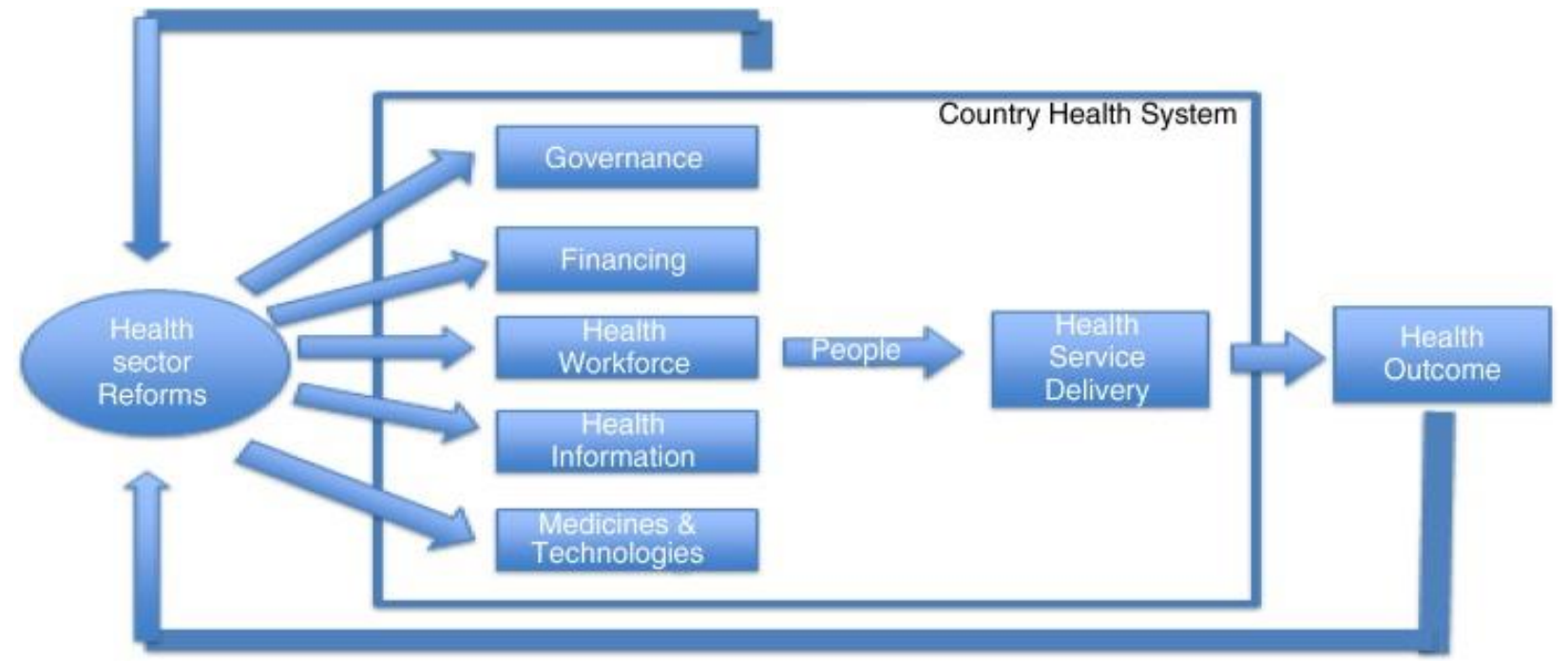

Figure 3 Senkubuge Theoretical Model, 2014

In this Senkubuge theoretical model, it recognizes the interaction between the health system building blocks and the people as the intervening variable for better service delivery and improved health outcome. According to Senkubuge, the five building blocks include governance, finance, health workforce, health information systems, and supply management systems. Senkubuge found out that the five points interlink and contribute toward the sixth point of interaction: the delivery of health services. Senkubuge underscores the central role of people in ensuring improved health outcomes. Also, all aspects of the six points of interaction take place within a general context that includes economic, social, political, environmental, and other factors that are not included in our analysis.

\subsubsection{Concept Framework Model}

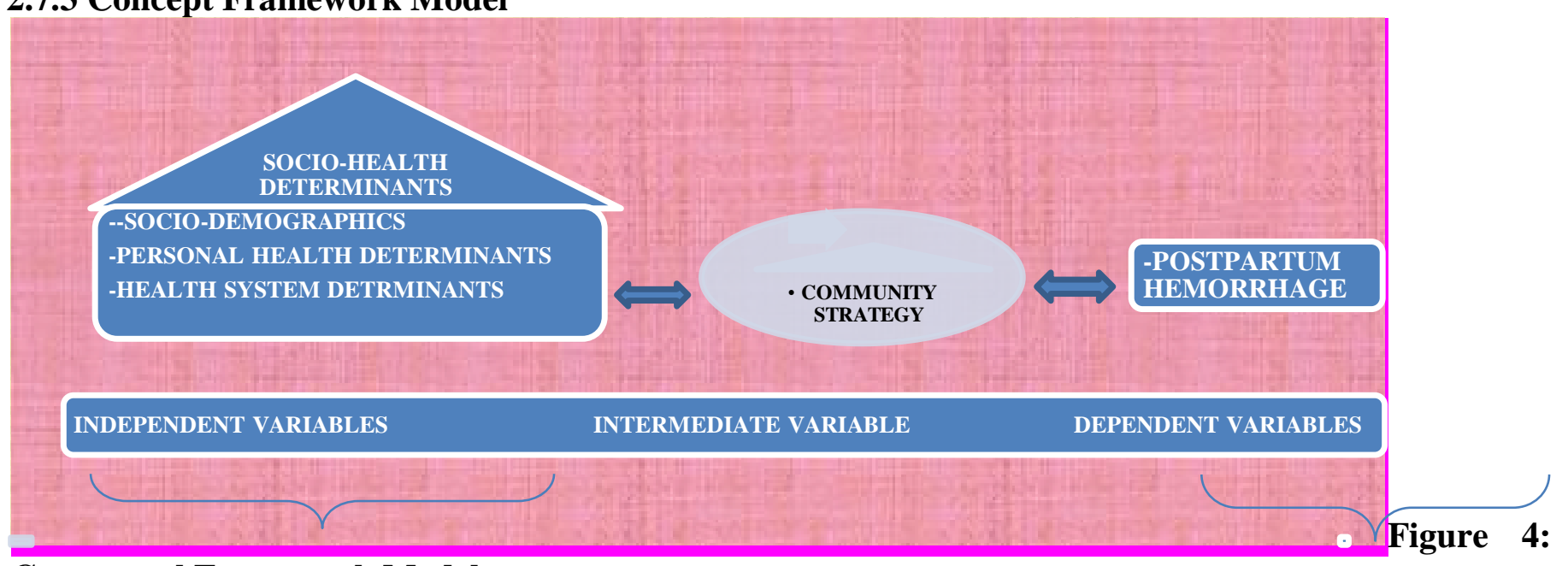

\section{Conceptual Framework Model}

\subsubsection{THEORETICAL FRAMEWORK}

In this conceptual model, socio-demographic determinants, and personal health determinants were the independent variables, postpartum hemorrhage was the dependent variable. Strengthening community strategy for improvement of socio-demographic characteristics and personal health characteristics reduce the chances of occurrence of postpartum hemorrhage. Prevention of occurrence of postpartum hemorrhage will improve health outcomes among women of reproductive age 15-49 years. High-quality health system factors and improvement of patient factors reduce the challenges and prevent occurrences of postpartum hemorrhage. 


\section{Methodology}

\subsection{Introduction}

This chapter consists of a study area, research design, study population, target population, sample size, sampling procedure, data collection procedure, data collection instruments, data management and analysis, and ethical consideration.

\subsection{Study Area}

The proposed study was conducted in the 12 level four public hospitals in Homa Bay County. Homa Bay County is one of the 47 Counties in Kenya. It is located in the former Nyanza province, in the Western part of the Country. Homa Bay County covers an area of 4,267.1 km² (CIDP, 2013). The County is divided into 8 administrative Sub-Counties namely: Rachuonyo South, Rachuonyo East, Rachuonyo North, Rangwe, Homa Bay Town, Ndhiwa, Suba South, and Suba North. The County has a total of 12 level four public hospitals (AWP, 2018) namely: Rachuonyo South Sub County Hospital, Rachuonyo East Sub County Hospital, Rangwe Sub-county Hospital, Rachuonyo North Sub County Hospital, Homa Bay Town Sub County Hospital, Ndhiwa Sub County Hospital, Suba South Sub County Hospital, and Suba North Sub County, Kandiege Sub County Hospital, Ogongo Sub County Hospital, Kisegi Sub County, Nyangiela Sub County Hospital (see figure 5).

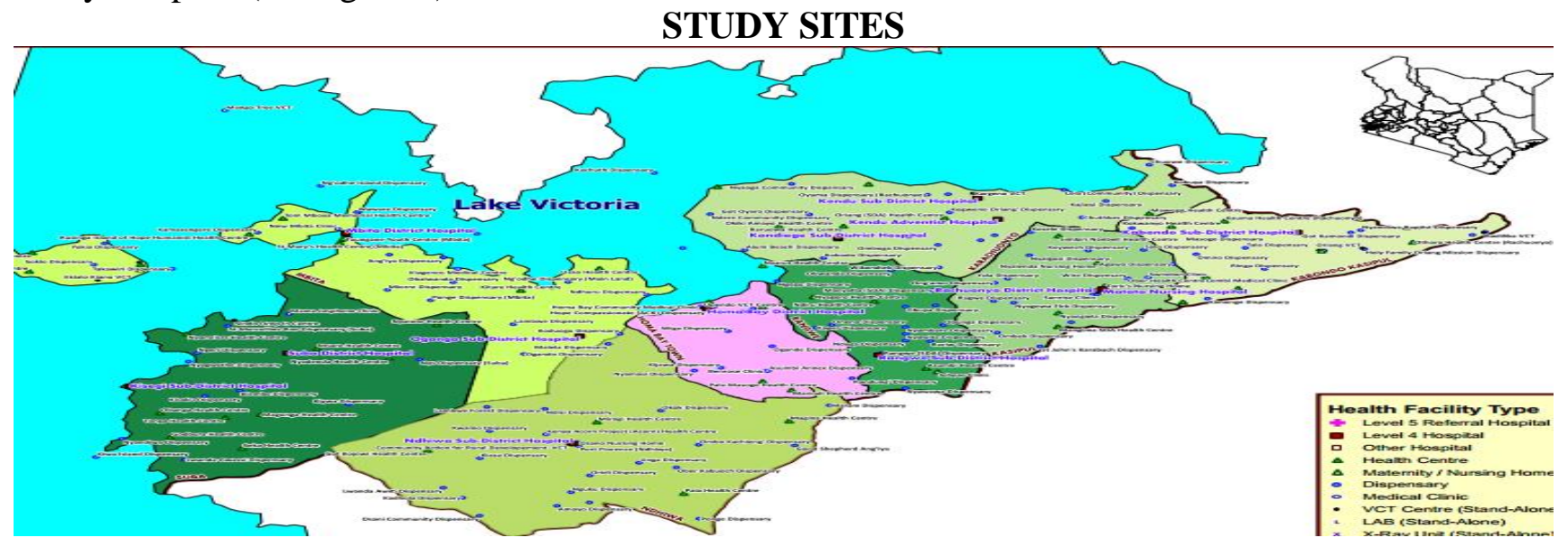

Figure 5: Map showing study locations and the distribution of health facilities in Homabay County

According to KNBS 2009, the population of Homa Bay County was 963 794. The total population of expectant mothers in 2017 in Homa Bay County was 46, 473.

The health care delivery system in Homa Bay County is comprised of public facilities, faith-based organizations and private facilities. The levels are as follows: 131 level 1 community units where CHVs and TBAs offer services; 250 level 2, and 3, and 12 level four public hospitals (GOK 2020).

\subsection{Research Design}

The study applied descriptive cross-sectional study design. Qualitative and quantitative methods were used for data collection and analysis. The descriptive study provided information concerning socio-health determinants of occurrence of postpartum hemorrhage; socio-demographic determinants, and personal health determinants of occurrence of postpartum hemorrhage among women of reproductive age.

\subsection{Study Population}

The study population comprised women of reproductive age 15-49 years in Homa Bay County. The total study population for this study was 46,473 who were women of reproductive age 15-49 years in Homa Bay County.

\subsection{Target population}


The study target population were the 400 women who delivered at the 12 level 4 public hospitals in Homa Bay County during the months of December, 2019 and January 2020.

\subsection{Sample Size Calculation}

The sample size for this study was calculated based on the formula adopted from Cochran's formula (1977) which allows calculation of an ideal sample size for a desired level of precision, confidence level, and estimated proportion of the attribute present in the population. It is considered for large and small populations. The formula is:

$$
\mathrm{n} \quad=\frac{(\mathrm{Z} \alpha / 2)^{2}(\mathrm{PQ})}{\mathrm{d}^{2}}
$$

Where:

$\mathrm{n}=$ the sample size (respondents who were interviewed)

$\mathrm{d}=0.05$ (the sampling margin error $(5 \%)$ that was accepted in this study

$\mathrm{Z} \alpha / 2=1.96$ ( $\mathrm{Z}$ score corresponding to a $95 \%$ confidence interval)

$\mathrm{P}=0.38$ (estimated proportion of postpartum hemorrhage in Homa Bay for categorical data).

$\mathrm{Q}=0.62(1-\mathrm{P})$

Substitution;

$$
\begin{array}{ll}
\mathrm{n} & =\frac{(1.96)^{2}(0.38 \times 0.62)}{0.05^{2}} \\
=363 & =362.3
\end{array}
$$

According to (UNFPA, 2014), 10\% of $\mathrm{n}$ was added for non-response. $10 \%$ of 363 equals 37 . The final sample size, taking into account the non-response is 400 postnatal women.

\subsection{Sampling Procedure}

The sample size of 400 postnatal women was proportionately allocated per level 4 public hospital in Homa Bay County. Table 3.2 indicates the way sample respondents were distributed throughout the Homa Bay County. The respondents were identified for a response using random sampling method where postnatal women were considered on first come, first enrolled basis. Only postnatal women who did not consent were skipped for the next postnatal woman. Every consented postnatal woman filled the postnatal woman questionnaire. The other questionnaire was filled by maternity In-Charge. The hospital's Matron filled the facility assessment questionnaire. Key Informant Interviews (KII) were also conducted involving the 12 Sub County Medical Officers of Health and, the one County Gynecologist for qualitative data.

\section{Table 2: Sampling Proportionate to the size of postnatal women}

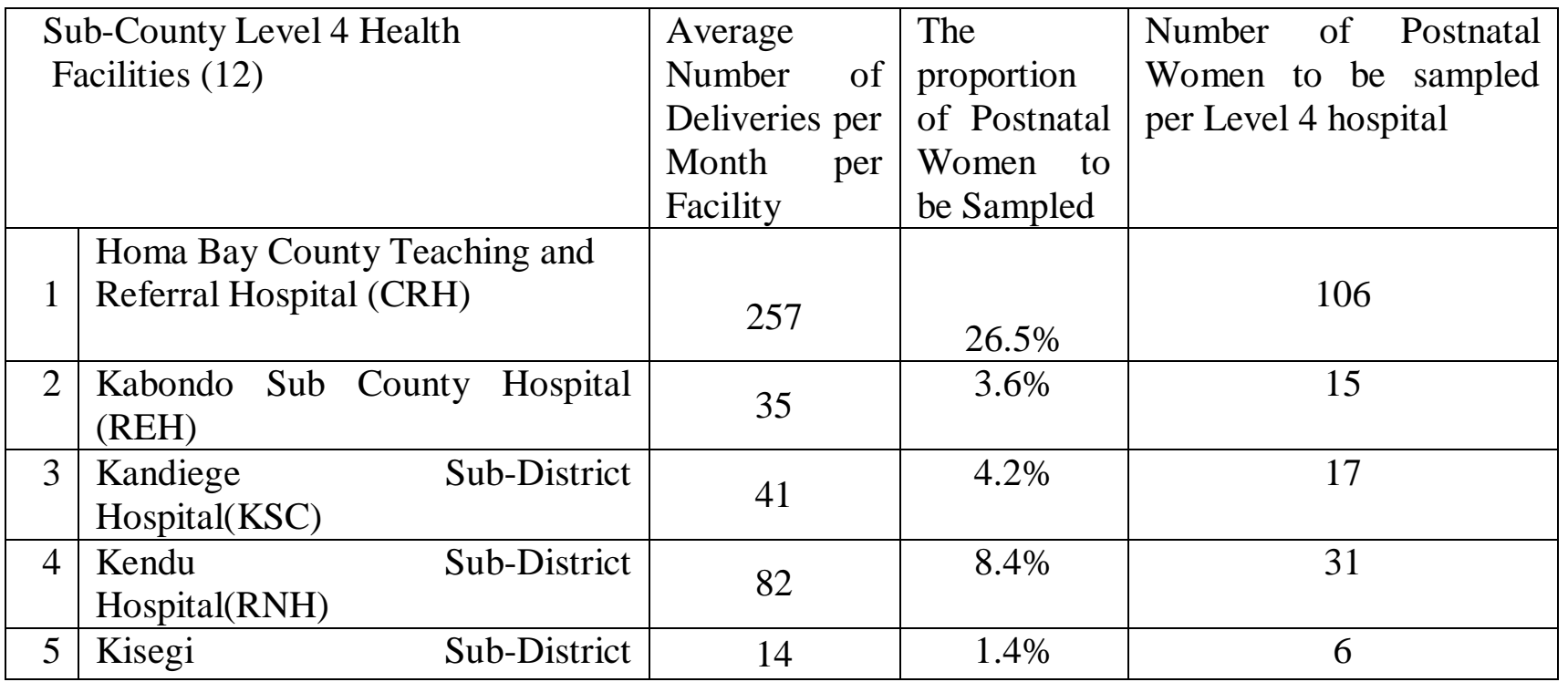




\begin{tabular}{|r|l|c|c|c|}
\hline & Hospital(KDH) & & & \\
\hline 6 & Mbita District Hospital(SNH) & 74 & $7.6 \%$ & 32 \\
\hline 7 & Ndhiwa District Hospital(NDH) & 131 & $13.5 \%$ & 10 \\
\hline 8 & $\begin{array}{l}\text { Nyangiela Sub District } \\
\text { Hospital(NSC) }\end{array}$ & 24 & $2.5 \%$ & 13 \\
\hline 9 & $\begin{array}{l}\text { Ogongo Sub-District } \\
\text { Hospital(OSC) }\end{array}$ & 31 & $3.2 \%$ & 72 \\
\hline 10 & Rachuonyo District Hospital(RSH) & 175 & $18 \%$ & 18 \\
\hline 11 & $\begin{array}{l}\text { Rangwe Sub-District } \\
\text { Hospital(RCH) }\end{array}$ & 45 & $4.6 \%$ & 26 \\
\hline 12 & Suba District Hospital(SSH) & 971 & $6.5 \%$ & 400 \\
\hline TOTAL & & & \\
\hline
\end{tabular}

\subsection{Data Collection Instruments}

There were two data collection questionnaires employed: the structured closed-ended questionnaires: Postnatal woman questionnaire, and the semi-structured Key Informants Interview questionnaire for collection of qualitative data. Other instruments used were phone recorder, lap top, note book, and a pen.

\subsubsection{Structured questionnaire}

There were three structured closed-ended questionnaires: Postnatal woman questionnaire, Maternity InCharge questionnaire, and the Matron's questionnaire.

The postnatal woman questionnaire was divided into three main sections as follows: section one targeted the socio-demographic determinants, and section two looked at the personal health characteristic. Key Informant Interview questionnaire also looked at the socio-demographic determinants, and personal health determinants. The structured questionnaires were administered by the research assistant while Key Informant Interview was carried out by myself. Each of the 12 level 4 public hospitals had one Research Assistant who administered the questionnaire to the postnatal women assigned to each of the hospitals as they were admitted at the postnatal Ward. The process of administration started with the checking of the records at the facility's postnatal Ward register to understand the condition of delivery in reference to occurrence of postpartum hemorrhage. The Research Assistant then follows-up the woman at the postnatal Ward, introduce self, and the purpose of the data collection, seek consent of the woman to administer the tool, and if granted consent, the respondent signs and research assistant moves on and administer the tool. The questionnaires that were correctly completed were analyzed.

\subsubsection{Semi-Structured Questionnaire}

This was composed of the Key Informant Interview (KII) questionnaire. The interview guide was used to collect data from healthcare providers through face-to-face interviews. The method was used to explore the socio-health determinants of occurrence of postpartum hemorrhage. They were then invited in turns into a prepared interview room set with all the data collection instruments. The Researcher introduced himself, and the purpose for the interview and sought consent of the respondents. All of them consented and each was taken through the questionnaire at own separate time. The Gynecologist was however interviewed virtually since he was on leave in Nairobi at the time of data collection. The Researcher conducted the interview and recorded the proceedings as Research Assistant took notes.

\subsection{Pre-testing}

This was conducted in order to test whether the questionnaire was valid. It was carried out at Kisumu County Hospital which is a level 4 public hospital. The pilot study achieved 4 respondents from the facility each filling one questionnaire. The researcher analyzed the data and determined whether the research tools used would lead to the achievement of the research objectives. The pre-test findings were used to modify the content, question structure, and sequencing of the questionnaire for example, it was realized that Key 
Informant Interview questionnaire needed restructuring for the interviewees to give appropriate response. On postnatal woman questionnaire, it was also realized that there was different interpretation on the question on "when was your last birth" where some understood it to mean, the current birth. The pre-test findings however were not included in the statistics of the main study.

\subsection{Reliability}

Reliability is the extent to which a test or procedure will produce similar results under constant conditions (Ogan, Karakuş, \& Kurşun, 2013). In this study, reliability was ensured through pre-testing of the research instruments after which review of the tools done guided by the pre-test findings.

\subsection{Validity}

Validity in research is the extent to which the research instruments measures what it is intended to measure, the design selected should be able to provide credible conclusions (Ogan et al., 2013). The research assistants were trained in the administration of the data collection tool. Validity was ensured by sharing the tools with supervisors and subject experts who ensured that the questions asked were valid to measure what they were intended to.

Qualitative and quantitative data were triangulated where data was compared either to support or determine points of contradictions (Hesse-Biber, 2012). Content validity was ensured through consultation with the supervisor who provided expert opinion on the data collection tools.

\subsection{Data collection Procedure}

There were two sets of data collected: Quantitative and qualitative data sets. After the recruitment of Research Assistant, the researcher convened a one-day training meeting for the 12 Research Assistants at the Homa Bay County Health Management Team (CHMT) Boardroom on $2^{\text {nd }}$ of December, 2019 from 10.00am to $3.00 \mathrm{pm}$. The purpose of this meeting was to install the Comcare application into the phones of the Research Assistants. The second deliverable for meeting was to orientate the Research Assistant on the three questionnaires that they were to administer by going through all the questions. Lastly, each of the 12 Research Assistants was assigned specific level 4 public hospital to collect data from depending on the preference of the Research Assistant. The Research Assistants reported to the various respective health facilities on $3^{\text {rd }}$ December, 2019, paying courtesy call at the Hospital Medical Superintendents, before proceeding to the postnatal Ward where again they reported to the Ward In-Charge for permission to conduct the data collection and access to the records of the women delivering at the health facilities.

The first respondent was the first woman who arrived immediately in the postnatal ward immediately the Research Assistant arrived at the postnatal ward. The Research Assistant did the exercise every day until the last respondent as per the proportion assigned the health facility. The Research Assistants were able to interview 400 postnatal women by $28^{\text {th }}$ December, 2019. During the data collection period, the Researcher, convened virtual meeting with the Research Assistants for updates and review of the progress and resolution of any matters arising from the field.

In between the days, the Research Assistants interviewed the facility Matron's and the Maternity In-charge.

\subsubsection{Research Assistants}

Data collection was done at the level four hospitals. The twelve Research Assistants who were required to have smart phone compatible with Comcare application, at least Diploma in Health-related course, and be ready to be engaged full time during the month of December, 2019. The Researcher oriented the Research Assistants, and installed them the Comcare application, and assigned the Research Assistants the hospitals to collect the data. Every day, the researcher held meeting with the Research Assistants for updates and progress assessment. After the structured questionnaires were done, the Researcher conducted Key Informant Interview which took place during the month of January, 2020. One research Assistant helped with notetaking during the Key Informant Interview. 


\subsection{Data management and analysis}

Quantitative data were collected, stored in password-protected laptops, processed through data editing and coding. Qualitative data was collected through recording and notetaking. This was stored in a password protected laptop as audio recording. The notes taken were also filed. After that, the audio recording was replayed and discussion captured according to the objectives. Thematic approach was employed in analysis of the qualitative data.

\section{Objective 1: Socio-demographic determinants of occurrence of postpartum hemorrhage among women of reproductive age15-49 years in Homa-Bay County}

The descriptive analysis was used to identify the socio demographic determinants such as age, residence, marital status, occupation, education, partner's occupation, and level of income. Categorical variables were analyzed using frequency distribution of categorical variables and means of continuous variables. The results were presented as frequencies and percentages, bivariate regression tables testing their association with occurrence of postpartum hemorrhage, and multiple regression on significance of precision model.

\section{Objective 2: Personal health determinants of occurrence of postpartum hemorrhage among women of reproductive age 15-49 years in Homa-Bay County.}

The analysis was to conduct a frequency, distribution and percentage tables. Second was a bivariate analysis testing association between independent variables of health systems functions and dependent variable the occurrence of PPH. Lastly the test done was multivariate logistic analysis testing the overall significance of association with the occurrence of PPH to establish crude odds rations and $95 \%$ confidence intervals. The associations provided the first step towards a multivariable logistic regression analysis. Results are consolidated in single tables for each set of personal health determinants including; the gravidity, age at first birth, gestation, previous experience of postpartum hemorrhage, role of health finance, governance structures, human resources for health and health service delivery factors. The results are presented as overall frequencies and percentages in table 4-8. In this analysis, a reference category (Ref) was selected to show the risk with other categories. Results are presented as frequencies (Table 4-8), percentages with odds ratios, $95 \%$ confidence intervals, and p-values. Variables with p-values $<0.05$ were considered statistically significant and were included in the multivariable analysis (Table 9). The influence was measured using adjusted odds ratios (AOR) with $95 \%$ confidence intervals.

Below is a brief description of the themes that were used for analysis:

1. Socio-demographic determinants: Age, parity, marital status, level of education, employment status, spouse occupation, income, type of house, house ownership, residence, religion, knowledge on $\mathrm{PPH}$, and current experience of $\mathrm{PPH}$

2. Personal Health determinants: Gravidity, Age at first Birth, ANC attendance, Gestation period, previous PPH, ANC profile test,

The coding process was done by NVIVO 12 PRO software, and each code and sub code were numbered in order, to reflect the analysis hierarchy.

Qualitative data was first recorded and transcribed and analyzed using content analysis where issues raised were organized using a thematic approach to be consistent with specific objectives of the study. Results from the quantitative and qualitative analysis were compared for concurrence or divergence

\subsection{Ethical Consideration}

Permission to conduct the study was sought from the School of Health Sciences and the Board of Post Graduate Studies. Ethical approval was sought from JOOUST Research and Ethics Review Committee. During data collection, voluntary informed written consent was sought and obtained from all the study participants after a detailed explanation of the purpose of the study. 
The participants were not required to write their names in the data collection tool for the maintenance of confidentiality. The health facilities and participants in the KIIs were identified with codes to ensure anonymity and confidentiality.

\section{Results}

\subsection{Introduction}

This chapter deals with data analysis of the of the frequency and percentage distribution of the respondents and study results which were to establish the socio-health determinants of occurrence of postpartum hemorrhage among women of reproductive age in Homa Bay County, Kenya. The analysis was done based on the research objectives which were to identify the socio-demographic determinants of occurrence of postpartum hemorrhage among women of reproductive age; and to determine the personal health determinants of occurrence of postpartum hemorrhage among women of reproductive age. Quantitative data was collected using structured questionnaire administered on the postnatal women, and maternity in-charges, while qualitative data was collected using key informant interview of the Sub County Medical Officers of Health and the County Gynecologist as key informants and finally, the facility assessment checklist was done. Factors included socio-demographic factors, and health characteristics factors.

\subsection{Frequency and percentage distribution of the respondents}

This section looks at the distribution of respondents per facility, age distribution, education level, marital status, place of residence, type of house, house ownership and monthly income, employment status, partner occupation.

\subsubsection{Distribution of Respondents per Facility}

The four hundred respondents were all female and were distributed in the percentage proportion of the monthly skilled deliveries. Homa Bay County level 4 had the majority of respondents 106(26.5\%) followed by Rachuonyo South level 4 hospitals with 72 (18\%). Kisegi level 4 hospital, and Nyangiela level 4 hospital were the least with $6(1.4 \%)$ and $10(2.5 \%)$ respectively.

Table 4.1 Distribution of the respondents per level four hospital

\begin{tabular}{|l|c|c|}
\hline Health Facility & No. respondents & \%Proportion \\
\hline Homa Bay County Level4 Hospital & 106 & $26.5 \%$ \\
\hline Kabondo Level 4 Hospital & 15 & $3.6 \%$ \\
\hline Kandiege Level 4 Hospital & 17 & $4.2 \%$ \\
\hline Kendu Level4 Hospital & 31 & $8.4 \%$ \\
\hline Kisegi Level4 Hospital & 6 & $1.4 \%$ \\
\hline Mbita Level4 Hospital & 32 & $7.6 \%$ \\
\hline Ndhiwa Level4 Hospital & 54 & $13.5 \%$ \\
\hline Nyangiela Level4 Hospital & 10 & $2.5 \%$ \\
\hline Ogongo Level4 Hospital & 13 & $3.2 \%$ \\
\hline Rachuonyo South Level4 Hospital & 72 & $18 \%$ \\
\hline Rangwe Level4 Hospital & 18 & $4.6 \%$ \\
\hline Suba Level4 Hospital & 26 & $6.5 \%$ \\
\hline TOTAL & $\mathbf{4 0 0}$ & $\mathbf{1 0 0 \%}$ \\
\hline
\end{tabular}




\subsubsection{Age distribution of the respondents}

The respondents were grouped into years with an interval of 5 according to the common WHO grouping in monitoring and evaluation of health systems on health outcomes. Majority of the respondents 197 (46.4\%) were between ages 15-24 years. Those participants who were above 35 years old were a paltry $35(8.3 \%)$. The age 40-44 years were the least 6(1.5\%). The respondents who were between ages 15-19 years were (79) $18.6 \%$. This is an indication of high teenage pregnancy in the County.

Table 4.2: Age distribution of respondents

\begin{tabular}{|l|c|c|}
\hline Age & No. respondents & Percentage \\
\hline $15-19$ & 74 & 18.5 \\
\hline $20-24$ & 111 & 27.7 \\
\hline $25-29$ & 118 & 29.5 \\
\hline $30-34$ & 63 & 15.8 \\
\hline $35-39$ & 28 & 7.0 \\
\hline $40-44$ & 6 & 1.5 \\
\hline TOTAL & $\mathbf{4 0 0}$ & $\mathbf{1 0 0 \%}$ \\
\hline
\end{tabular}

\subsubsection{Education level of the respondents}

The study found out that college and university school leavers were only 51(12.7\%). This implies that most of the women in Homa Bay County drop out of school before attaining tertiary education.

Table 4.3: Education level of the respondents

\begin{tabular}{|l|c|c|}
\hline Education & No. respondents & Percentage \\
\hline Primary & 187 & 46.7 \\
\hline Secondary & 162 & 40.6 \\
\hline College/University & 51 & 12.7 \\
\hline TOTAL & $\mathbf{4 0 0}$ & $\mathbf{1 0 0 \%}$ \\
\hline
\end{tabular}

\subsubsection{Marital status of the respondents}

There were $89(22.2 \%)$ respondents who had no spouses. These were either single, widowed, or separated. Majority $311(77.8 \%)$ of the respondents had spouses.

Table 4.3: Marital status of the respondents

\begin{tabular}{|l|c|c|}
\hline Education & No. respondents & Percentage \\
\hline No spouse & 89 & 22.2 \\
\hline Spoused & 311 & 77.8 \\
\hline TOTAL & $\mathbf{4 0 0}$ & $\mathbf{1 0 0 \%}$ \\
\hline
\end{tabular}

\subsubsection{Place of residence}

The study showed that $308(76.9 \%)$ respondents live in the rural. This implies that most the population in Homa Bay County are living in the rural areas. 
Table 4.4: Place of residence of the respondents

\begin{tabular}{|l|c|c|}
\hline Residence & No. respondents & Percentage \\
\hline Urban & 92 & 23.1 \\
\hline Rural & 308 & 76.9 \\
\hline TOTAL & $\mathbf{4 0 0}$ & $\mathbf{1 0 0 \%}$ \\
\hline
\end{tabular}

\subsubsection{Type of house of the respondents}

There were $287(71.8 \%)$ of the respondents who lived in a semi-permanent house. Only $113(28.2 \%)$ respondents lived in a permanent house. This implied that majority of the respondents had low economic status.

Table 4.5: Type of house of the respondents

\begin{tabular}{|l|c|c|}
\hline Type of House & No. respondents & Percentage \\
\hline Permanent & 113 & 28.2 \\
\hline Semi-permanent & 287 & 71.8 \\
\hline Total & $\mathbf{4 0 0}$ & $\mathbf{1 0 0 \%}$ \\
\hline
\end{tabular}

\subsubsection{House ownership of the respondents}

The research shows that majority $268(67.1 \%)$ of the respondents owned houses. However, 20 (5\%) were either in the parents' house or relatives' house.

Table 4.6: House ownership of the respondent

\begin{tabular}{|l|c|c|}
\hline Education & No. respondents & Percentage \\
\hline Own home & 268 & 67.1 \\
\hline Rental & 112 & 27.9 \\
\hline Parents House & 18 & 4.5 \\
\hline Relative House & 2 & 0.5 \\
\hline TOTAL & $\mathbf{4 0 0}$ & $\mathbf{1 0 0 \%}$ \\
\hline
\end{tabular}

\subsubsection{Monthly income}

According to this research, 83 (20.5\%) of the respondents had below Ksh.1,000 monthly income while only $90(22.6 \%)$ had monthly income of above Ksh.10,000. More than half of the respondents $227(56.8 \%)$ had between Ksh.1,000 to Ksh.10,000 as monthly income. This means that most women are not empowered and came from poor families.

Table 4.7: Monthly income of the respondent

\begin{tabular}{|l|c|c|}
\hline Monthly income & No. respondents & Percentage \\
\hline Less than 1000 KSh & 83 & 20.5 \\
\hline $1000-5000 \mathrm{Ksh}$ & 114 & 28.5 \\
\hline $5000-10000 \mathrm{Ksh}$ & 113 & 28.3 \\
\hline
\end{tabular}




\begin{tabular}{|l|c|c|}
\hline Above $10000 \mathrm{Ksh}$ & 90 & 22.6 \\
\hline Total & $\mathbf{4 0 0}$ & $\mathbf{1 0 0}$ \\
\hline
\end{tabular}

\subsubsection{Employment status of the respondents}

There were 289 (72.2\%) of the respondents who were self-employed. Casuals were 79 (19.8) while only 32 $(8 \%)$ had salaried jobs. This means that there is a great unemployment in Homa Bay County.

Table 4.8: Employment status of the respondent

\begin{tabular}{|l|c|c|}
\hline Employment status & No. respondents & Percentage \\
\hline Casual job & 79 & 19.8 \\
\hline Salaried & 32 & 8 \\
\hline Self Employed & 289 & 72.2 \\
\hline Total & $\mathbf{4 0 0}$ & $\mathbf{1 0 0 \%}$ \\
\hline
\end{tabular}

\subsubsection{Occupation of the partner of the respondents}

The study revealed that most of the partners of the respondents $172(43.1 \%)$ were self-employed. Those working as casuals were $91(22.9 \%)$ while unemployed partners were 69 (17.3\%). This confirms the high rate of unemployment as seen earlier in the table of employment status of the respondents.

Table 4.9: Occupation of the partner of the respondent

\begin{tabular}{|l|c|c|}
\hline Partner occupation & No. respondents & Percentage \\
\hline Casual job & 91 & 22.9 \\
\hline Self-employed & 172 & 43.1 \\
\hline Unemployed & 69 & 17.3 \\
\hline Not Applicable & 67 & 16.7 \\
\hline TOTAL & $\mathbf{4 0 0}$ & $\mathbf{1 0 0 \%}$ \\
\hline
\end{tabular}

4.2 Socio-demographic determinants of occurrence of postpartum haemorrhage among women of reproductive age

This deals with socio-demographic determinants, and personal health determinants.

\subsubsection{Socio-demographic determinants of occurrence of postpartum hemorrhage}

The section looks at Marital status and the cumulative influence of socio-demographic determinants on occurrence of postpartum hemorrhage.

\subsubsection{Influence of marital status on occurrence of postpartum hemorrhage}

It was found to be statistically significant in influencing occurrence of postpartum haemorrhage with Pearson's Chi-square 4.32 (P-value $=0.038$ ). It was also noted that those having spouses were 1.19 times more likely to experience postpartum hemorrhage.

Table 4.10: Influence of Marital status on occurrence of postpartum hemorrhage

\begin{tabular}{|l|l|l|l|l|l|l|}
\hline Marital status & No & No & Yes & Yes & Total & \multicolumn{1}{l|}{ Total } \\
\cline { 2 - 8 } & Number & Percent & Number & Percent & Number & Percent \\
\hline No spouse & 90 & 23.6 & 4 & 9.5 & 94 & 22.2 \\
\hline
\end{tabular}




\begin{tabular}{|l|r|r|r|r|r|r|}
\hline Having spouse & 292 & 76.4 & 38 & 90.5 & 330 & 77.8 \\
\hline Pearson chi $2(1)=4.3206 \mathrm{Pr}=0.038$ & & & & \\
\hline
\end{tabular}

\subsubsection{Socio-demographic determinants on occurrence of postpartum hemorrhage}

Secondary school leavers were 3.34 times more likely to experience postpartum hemorrhage while those respondents who are below 25 years old were 1.025 times likely to experience postpartum hemorrhage. Those leaving in rural area were 1.2 times more likely to experience postpartum hemorrhage while women who are self employed were 0.78 times less likely to experience postpartum hemorrhage compared to those who are employed who were salaried at 1.6 likelihood of experience postpartum hemorrhage at confidence interval of $95 \%$.

Table 4.11: Socio-demographic determinants on occurrence of postpartum hemorrhage

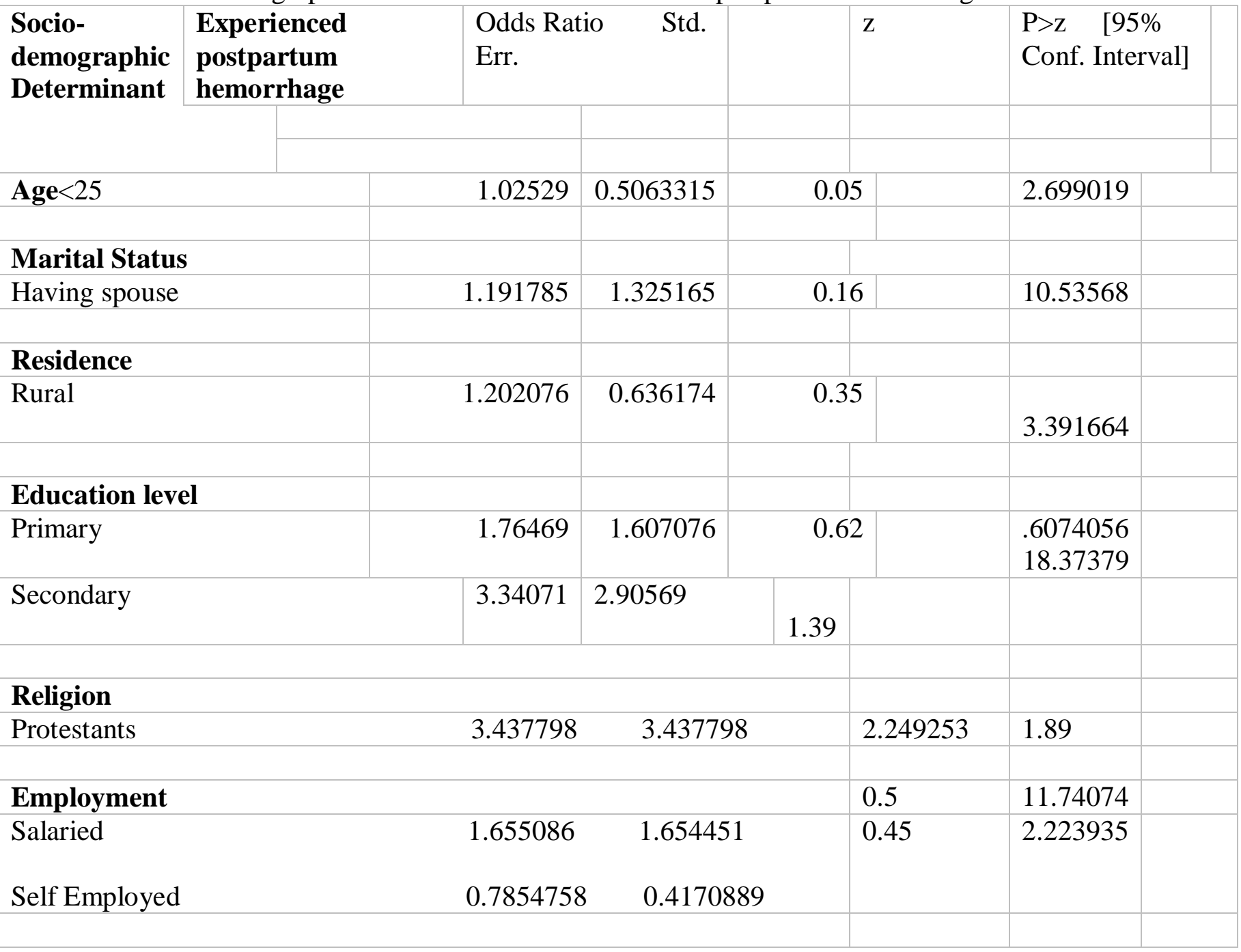

\subsubsection{Personal health determinants of occurrence of postpartum hemorrhage}

Some of the characteristics with statistical significance included gravidity, ANC, and previous postpartum hemorrhage. The section will also have multiple regression analysis for the health characteristics.

\subsubsection{Influence of gravidity on occurrence of postpartum hemorrhage}

The study showed that gravidity, had statistical significance in the occurrence of postpartum hemorrhage among postnatal women with Pearson Chi-square of 11.76 (P-Value=0.008). It was more or less the same for postnatal women of at most gravida two (62.2\%) not to experience postpartum hemorrhage as was those who were at least gravida three $(64.5 \%)$ to experience postpartum hemorrhage. According to the study, 
postnatal women who were below fifteen years of age who experienced postnatal hemorrhage were twice $(4.8 \%)$ those who were above thirty years of age who experienced postpartum hemorrhage. However, it was notable that the percentage of postnatal women who were below fifteen years who did not experience postpartum hemorrhage and those who experienced postpartum hemorrhage were more less the same unlike the percentage of postnatal women who were above thirty years of age and experienced postpartum hemorrhage who were five times the percentage of those who were above thirty years who did not experience postpartum hemorrhage.

Table 4.11 Influence of gravidity on occurrence of postpartum hemorrhage

\begin{tabular}{|l|l|l|l|l|l|l|l|}
\hline Gravida & No & No & Yes & Yes & Total & \multicolumn{1}{l|}{ Total } \\
\cline { 2 - 8 } & Number & Percent & Number & Percent & Number & Percent \\
\hline First & 120 & 36.6 & 5 & 16.1 & 125 & 34.8 \\
\hline Second & 84 & 25.6 & 6 & 19.4 & 90 & 25.1 \\
\hline Third & 60 & 18.3 & 13 & 41.9 & 73 & 20.3 \\
\hline Above Forth & 64 & 19.5 & 7 & 22.6 & 71 & 19.8 \\
\hline Pears & & & & & &
\end{tabular}

Pearson $\operatorname{chi} 2(3)=11.7667 \mathrm{Pr}=0.008$

\subsubsection{Influence of previous postpartum hemorrhage on occurrence of postpartum hemorrhage}

Previous postpartum hemorrhage was statistically significant. Those who had previous experience of postpartum hemorrhage were five times the percentage of those who were above thirty years who did not experience postpartum hemorrhage. Ninety seven percent of women who had not experienced postpartum hemorrhage had occurrence of postpartum hemorrhage. It was also noted that more than half of all postnatal women who had postpartum hemorrhage $(51.6 \%)$ had self-employed husbands. It was more or less the same for postnatal women of at most gravida two $(62.2 \%)$ not to experience postpartum hemorrhage as was those who were at least gravida three $(64.5 \%)$ to experience postpartum hemorrhage.

Table 4.12 Influence of previous postpartum hemorrhage on occurrence of postpartum hemorrhage

\begin{tabular}{|l|l|l|l|l|l|l|l|}
\hline \multirow{2}{*}{ Previous PPH } & No & No & Yes & Yes & Total & Total \\
\cline { 2 - 8 } & Number & Percent & Number & Percent & Number & Percent \\
\hline No & 374 & 97.9 & 18 & 42.9 & 392 & 92.5 & No \\
\hline Yes & 8 & 2.1 & 24 & 57.1 & 32 & 7.5 & Yes \\
\hline
\end{tabular}

Pearson $\operatorname{chi} 2(1)=164.3370 \operatorname{Pr}=0.01$

\subsubsection{Influence of ANC on occurrence of postpartum hemorrhage}

Attendance of antenatal clinic was statistically insignificant but the study showed that the percentage of those postnatal women who attended or did not attend antenatal clinic was directly proportional to the percentage occurrence of postpartum hemorrhage.

Table 4.13: Influence of ANC on occurrence of postpartum hemorrhage

\begin{tabular}{|l|l|l|l|l|l|l|}
\hline \multirow{2}{*}{ Gravida } & No & No & Yes & Yes & Total & Total \\
\cline { 2 - 8 } & Number & Percent & Number & Percent & Number & Percent \\
\hline First Trimester & 145 & 38.9 & 8 & 19.5 & 153 & 37 \\
\hline Second Trimester & 186 & 49.9 & 27 & 65.9 & 213 & 51.4 \\
\hline Third Trimester & 42 & 11.3 & 6 & 14.6 & 48 & 11.6 \\
\hline Pearson chis & & & & & &
\end{tabular}

Pearson $\operatorname{chi} 2(2)=5.9450 \quad \operatorname{Pr}=0.051$ 


\subsubsection{Multiple regression on influence of health characteristics on occurrence of postpartum hemorrhage}

Health characteristics collectively have statistical significance with logistic regression chi-square 62.08 (PValue $=0.01$ ) Pseudo R2 0.3806. The study showed that postnatal women who had unemployed spouses were 0.900 unlikely occurrence of postpartum hemorrhage compared to those whose spouses were either employed or self-employed who 2.28 times likely to have occurrence of postpartum hemorrhage. The study indicated that it occurrence of postpartum hemorrhage is 0.914 less likely in gestations below 37 weeks compared to delivery after 37 weeks. Looking at gravidity, it is 0.86 less likely to experience occurrence of postpartum hemorrhage for gravida two unlike gravida one. Gravida three and above is 1.86 times riskier experiencing occurrence of postpartum hemorrhage while having first birth at below 20 years of age is 1.73 times riskier for occurrence of postpartum hemorrhage compared to having first birth at age above 20 years. It was also notable that starting ANC at second trimester was worse than starting antenatal clinic at either first trimester or third trimester.

This information supports the result in table 4.4 below about the period the mother started ANC visits;

"Failure to attend ANC or inadequate attendance. These hinder early diagnoses of complications. Late recognition of conditions that cause antepartum and postpartum hemorrhage. "KIIO3

Past experience of postpartum hemorrhage is more than 60 times likelihood of re-occurrence of postpartum hemorrhage. For the stakeholders given the statistical significance, it means that the health characteristics: Age at first birth, gravidity, and gestation attended ANC, previous occurrence of postpartum hemorrhage, and partner's occupation are factors influencing occurrence of postpartum hemorrhage.

Table 4.14: Personal Health determinants of occurrence of postpartum hemorrhage

\begin{tabular}{|c|c|c|c|c|c|}
\hline Health Characteristic & Odds Ratio & Std. Err. & $\mathrm{z}$ & $\mathrm{P}>\mathrm{Z}$ & $\begin{array}{l}\text { [95\% Conf. } \\
\text { Interval] }\end{array}$ \\
\hline \multicolumn{6}{|l|}{ Partner's Occupation } \\
\hline Self-employed & 2.284465 & 1.70672 & 1.11 & 0.269 & $\begin{array}{l}.5282668 \\
9.879062\end{array}$ \\
\hline Unemployed & 0.9003514 & 1.178604 & -0.08 & 0.936 & $\begin{array}{l}.0692066 \\
11.71322\end{array}$ \\
\hline Not Applicable & 1.435676 & 1.640485 & 0.32 & 0.752 & $\begin{array}{l}.1529064 \\
13.47992\end{array}$ \\
\hline \multicolumn{6}{|l|}{ Gestation } \\
\hline$<37$ weeks & 0.9145404 & 0.5585335 & -0.15 & 0.884 & $\begin{array}{l}.2762817 \\
3.027288\end{array}$ \\
\hline \multicolumn{6}{|l|}{ Gravida } \\
\hline Second & 0.8681142 & 0.8485413 & -0.14 & 0.885 & $\begin{array}{l}.1278106 \\
5.896399\end{array}$ \\
\hline Third & 1.859912 & 1.713803 & 0.67 & 0.501 & $\begin{array}{l}.3056038 \\
11.31947\end{array}$ \\
\hline Above Forth & 1.856964 & 1.735057 & 0.66 & 0.508 & $\begin{array}{c}.2974967 \\
11.5911\end{array}$ \\
\hline \multicolumn{6}{|l|}{ Age first birth } \\
\hline$<20$ & 1.725134 & 1.292415 & 0.73 & 0.467 & $\begin{array}{c}.3973108 \\
7.49058\end{array}$ \\
\hline \multicolumn{6}{|c|}{ Experience of Postpartum Hemorrhage Previously } \\
\hline Yes & 60.08835 & 45.85268 & 5.37 & 0.000 & 13.46632 \\
\hline
\end{tabular}




\begin{tabular}{|c|c|c|c|c|}
\hline & & & & 268.1216 \\
\hline \multicolumn{5}{|c|}{ When Started ANC } \\
\hline Second Trimester & 3.734737 & 2.560602 & $1.92 \quad 0.055$ & $\begin{array}{l}.9742296 \\
14.31722\end{array}$ \\
\hline Third Trimester & 2.052711 & 2.528165 & $0.58 \quad 0.559$ & $\begin{array}{l}.1836408 \\
22.94492\end{array}$ \\
\hline _cons & 0.004497 & 0.0060963 & -3.990 .000 & $\begin{array}{l}.0003155 \\
.064099\end{array}$ \\
\hline
\end{tabular}

\section{Discussion}

According to this study, gravidity was statistically significant Pearson Chi-square 11.76 (P-Value=0.008). Women who were in three or four were 1.8 times more likely to experience postpartum hemorrhage unlike those in second gravida. Elkhoudri, et al.(2015) also indicated that women who had been pregnant more than three times reported significantly more postpartum complications. This study was in line with a study done in Indonesia by Fortney et al. (1988) showing that postpartum hemorrhage was the most common cause of maternal death among women who were in gravida three and above. It was also established that women age below 25 were 1.03 times more likely to experience postpartum hemorrhage, this disagrees with study by Asamoah et al. (2011) stating that hemorrhage is highest in the age group 35-39 years, followed by 30-34 years, however another study by Elkhoudri, et al.(2015) stated that the age at childbearing over 35 years increases several maternal complications like pregnancy-induced hypertension, dystocia. Additionally, married women were at a higher risk of experiencing postpartum hemorrhage as compared to the single women, The study is in line with a study done in Ghana by Asamoah et al. (2011) which revealed that married women had a higher risk of dying from hemorrhage compared to their single counterparts. Awareness of postpartum hemorrhage had a significant association with experiencing postpartum hemorrhage with $(\mathrm{p}=<0.0001)$, this is closely related to a study in northern Nigeria by Minkler et al. (2012) revealing that community mobilization can have a significant impact on the successful distribution and uptake of a potentially life-saving health intervention, in turn helping promote policy change. Postnatal women who were self-employed were 0.78 less likely to experience postpartum hemorrhage. This is in line with a finding by Dofany et al. ( 2009) who indicated that Prenatal care was related significantly to the income of the woman's household.

Majority of the patient factors that influence occurrence of postpartum hemorrhage were insignificant except for the women who started antenatal clinic at their second trimester who were more likely to experience postpartum hemorrhage as compared to those who started at the first trimester the findings of this study is close to the findings done by Haftu et al (2018) which observed that postpartum hemorrhage complication was reduced by $81.2 \%$ among women's with complete adherence to antenatal care visit.

\section{Recomendations}

This chapter gives recommendations according to the findings of this research. It also proposes the new research model for desirable outcomes.

According to the study result, age, education, marital status, and place of residence or accessibility of health care facility are key in preventing occurrence of postpartum hemorrhage. The study recommendation is that the stakeholders should improve systems to see girls improve their education beyond primary school, improve age and accessibility of health care facilities. Gravidity, gestation period, attendance of antenatal care clinic in the first semester, previous experience of postpartum hemorrhage had statistical significance in the occurrence of postpartum hemorrhage. The study therefore recommends that women should be encouraged to have fewer gravida, ensure safety during pregnancy, and be extra careful once experienced postpartum hemorrhage. It is recommended that community strategy should take central role to promote awareness. Further, according to the study results, empowering women economically reduces chances of postpartum hemorrhage. Stakeholders therefore should advocate for the empowerment of women. Since 
health characteristics collectively have statistically significant, the stakeholders should put systems to improve them.

FIGURE 4.9: EMERGING MODEL: FOCUSED COMMUNITY STRATEGY REDUCING OCCURRENCE OF POSTPARTUM HEMORRHAGE

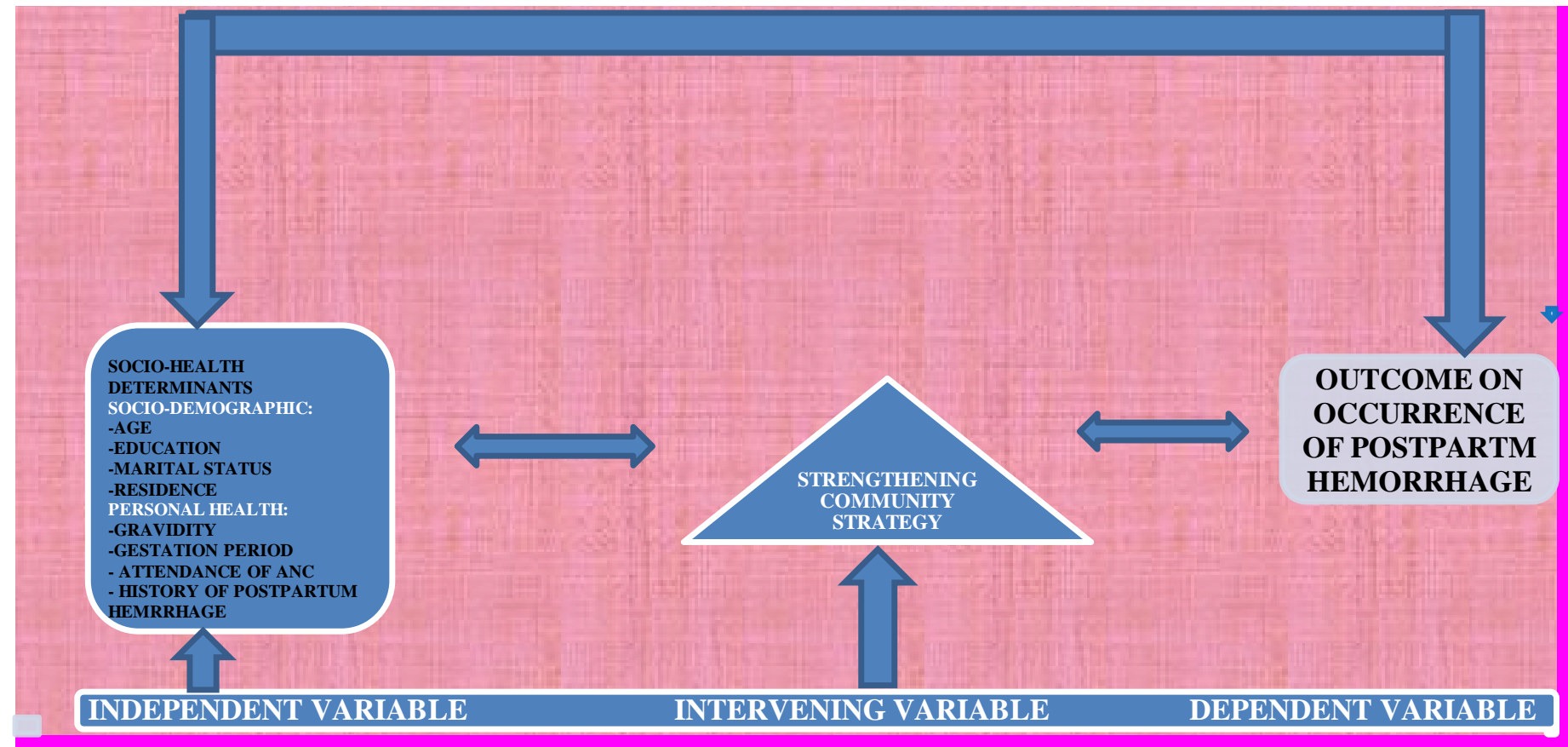

\section{Reference}

[1] Abbott, B. B., \& Bordens, K. S. (2011). Research design and methods: A process approach. In: New York: McGraw-Hill.

[2] Almeida, J. M., Eager, D. L., Vernon, M. K., \& Wright, S. J. (2004). Minimizing delivery cost in scalable streaming content distribution systems. IEEE Transactions on Multimedia, 6(2), 356-365.

[3] Bale, J. R., Stoll, B. J., \& Lucas, A. O. (2003). Reducing maternal mortality and morbidity.

[4] BANK, W. (2006). Oral misoprostol in preventing postpartum haemorrhage in resource-poor communities: a randomised controlled trial. The Lancet, 368(9543), 1248-1253.

[5] Banke-Thomas, A., Banke-Thomas, O., Kivuvani, M., \& Ameh, C. A. (2017). Maternal health services utilization by Kenyan adolescent mothers: analysis of the Demographic Health Survey 2014. Sexual \& Reproductive Healthcare, 12, 37-46.

[6] Baqui, A. H., Ahmed, S., El Arifeen, S., Darmstadt, G. L., Rosecrans, A. M., Mannan, I., ... Seraji, H. R. (2009). Effect of timing of first postnatal care home visit on neonatal mortality in Bangladesh: an observational cohort study. BMJ, 339, b2826.

[7] Beck, U., \& Grande, E. (2010). Varieties of second modernity: The cosmopolitan turn in social and political theory and research. The British journal of sociology, 61(3), 409-443.

[8] Bhutta, Z. A., Das, J. K., Bahl, R., Lawn, J. E., Salam, R. A., Paul, V. K., . . Chou, V. B. (2014). Can available interventions end preventable deaths in mothers, newborn babies, and stillbirths, and at what cost? The Lancet, 384(9940), 347-370.

[9] Blanc, A. K., Warren, C., McCarthy, K. J., Kimani, J., Ndwiga, C., \& RamaRao, S. (2016). Assessing the validity of indicators of the quality of maternal and newborn health care in Kenya. Journal of global health, 6(1).

[10] Blencowe, H., Cousens, S., Chou, D., Oestergaard, M., Say, L., Moller, A.-B., . . Lawn, J. (2013). Born too soon: the global epidemiology of 15 million preterm births. Reproductive health, 10(1), S2.

[11] Borghi, J., Ensor, T., Neupane, B. D., \& Tiwari, S. (2006). Financial implications of skilled attendance at delivery in Nepal. Tropical Medicine \& International Health, 11(2), 228-237. 
[12] Brenner, S., De Allegri, M., Gabrysch, S., Chinkhumba, J., Sarker, M., \& Muula, A. S. (2015). The quality of clinical maternal and neonatal healthcare-a strategy for identifying 'routine care signal functions'. PloS one, 10(4), e0123968.

[13] Brian K Omondi , Factors influencing service delivery in Hospitals: case study of Nairobi County

[14] Callaghan, L., Winters, J., \& McGrath, L. Maternal, Infant and Child Nutrition and Nurture: Relational, Bio-cultural and Spatial Perspectives.

[15] Cameron, M., \& Robson, S. (2006). Vital statistics: an overview. A Textbook of Postpartum Hemorrhage in Resource-Poor Countries: A Comprehensive Guide to Evaluation, Management, and Surgical Intervention. 1st ed. Kirkmahoe, Dumfriesshire, UK: Sapiens Publishing, 17-34.

[16] Cherry, A. L. (2015). Shifting Our Focus from Retribution to Social Justice: An Alternative Vision for the Treatment of Pregnant Women Who Harm Their Fetuses. JL \& Health, 28, 6.

[17] Creswell, J. W., \& Creswell, J. D. (2017). Research design: Qualitative, quantitative, and mixed methods approach Sage publications.

[18] Dolan, G., Ter Kuile, F. O., Jacoutot, V., White, N., Luxemburger, C., Malankirii, L., . . Nosten, F. (1993). Bed nets for the prevention of malaria and anemia in pregnancy. Transactions of the Royal Society of Tropical Medicine and Hygiene, 87(6), 620-626.

[19] Dolea, C., AbouZahr, C., \& Stein, C. (2003). Global burden of maternal hemorrhage in the year 2000. Retrieved from

[20] Duke, T., Yano, E., Hutchinson, A., Hwaihwanje, I., Aipit, J., Tovilu, M., . . Lagani, W. (2016). Large-scale data reporting of paediatric morbidity and mortality in developing countries: it can be done. Archives of disease in childhood, 101(4), 392-397.

[21] Eleje, G. U., Ezugwu, E. C., Eke, A. C., Eleje, L. I., Ikechebelu, J. I., Afiadigwe, E. A., . . Ezeama, C. O. (2016). Diagnostic performance of the placental alpha-microglobulin-1 test in women with prolonged pre-labour rupture of membranes. The Journal of Maternal-Fetal \& Neonatal Medicine, 29(8), 1291-1296.

[22] Ergo, A., Eichler, R., Koblinsky, M., \& Shah, N. (2011). Strengthening health systems to improve maternal, neonatal and child health outcomes: a framework. Washington, DC: US Agency for Development, Maternal, and Child Health Integrated Program.

[23] Ezegwui, H., Onoh, R. C., Ikeako, L., Onyebuchi, A., Umeorah, J., Ezeonu, P., \& Ibekwe, P. (2013). Investigating maternal mortality in a public teaching hospital, Abakaliki, Ebonyi State, Nigeria. Annals of medical and health sciences research, 3(1), 75-80.

[24] Felarmine, M., Joachim, O., \& Agina, O. (2016). Facility factors influencing utilization of active management of the third stage of labour among skilled birth attendants in Kiambu county, Kenya. The Pan African medical journal, 25(Suppl 2).

[25] Graham, W. J., \& Campbell, O. M. (1992). Maternal health and the measurement trap. Social science \& medicine, 35(8), 967-977.

[26] Hahn, E. D., \& Doh, J. P. (2006). Using Bayesian methods in strategy research: an extension of Hansen et al. Strategic Management Journal, 27(8), 783-798.

[27] Hailu, A., \& Kebede, D. (1994). High-risk pregnancies in urban and rural communities in the central part of Ethiopia. East African medical journal, 71(10), 661-666.

[28] Hancock, A., Weeks, A. D., \& Lavender, D. T. (2015). Is accurate and reliable blood loss estimation the crucial step'in early detection of postpartum haemorrhage: an integrative review of the literature. BMC pregnancy and childbirth, 15(1), 230.

[29] Health, U. D. o., \& Services, H. (2016). Agency for Healthcare Research and Quality (AHRQ). 2014. Primary Care Workforce Facts and Stats(3).

[30] Hesse-Biber, S. (2012). Feminist approaches to triangulation: Uncovering subjugated knowledge and fostering social change in mixed methods research. Journal of Mixed Methods Research, 6(2), 137146.

[31] Kagema, F., Ricca, J., Rawlins, B., Rosen, H., Mukhwana, W., Lynam, P., . . Miheso, A. (2011). Quality of care for prevention and management of common maternal and newborn complications: findings from a National Health Facility Survey in Kenya - are services provided according to international standards. Baltimore: Jhpiego. 
[32] Kane, C. (1992). CL Kane and MPA Fisher, Phys. Rev. B 46, 15233 (1992). Phys. Rev. B, 46, 15233.

[33] KDHS. (2015). 2014 KDHS key findings.

[34] Khan, K. S., Wojdyla, D., Say, L., Gülmezoglu, A. M., \& Van Look, P. F. (2006). WHO analysis of causes of maternal death: a systematic review. The Lancet, 367(9516), 1066-1074.

[35] Kinuthia, K., Stephenson, M., \& Maogoto, E. (2019). Management of postpartum hemorrhage in a rural hospital in Kenya: a best practice implementation project. JBI database of systematic reviews and implementation reports.

[36] Kitui, J., Lewis, S., \& Davey, G. (2013). Factors influencing place of delivery for women in Kenya: an analysis of the Kenya demographic and health survey, 2008/2009. BMC pregnancy and childbirth, 13(1), 40.

[37] Kitui, J. E., Dutton, V., Bester, D., Ndirangu, R., Wangai, S., \& Ngugi, S. (2017). Traditional Birth Attendant reorientation and Motherpacks incentive's effect on health facility delivery uptake in Narok County, Kenya: An impact analysis. BMC pregnancy and childbirth, 17(1), 125.

[38] Kiwuwa, M. S., \& Mufubenga, P. (2008). Use of antenatal care, maternity services, intermittent presumptive treatment and insecticide-treated bed nets by pregnant women in Luwero district, Uganda. Malaria Journal, 7(1), 44.

[39] Kosińska-Kaczyńska, K., Szymusik, I., Bomba-Opoń, D., Olejek, A., Sławska, H., Zimmer, M., ... Seremak-Mrozikiewicz, A. (2016). Perinatal outcome according to chorionicity in twins-a Polish multicenter study. Ginekologia polska, 87(5), 384-389.

[40] Kumar, R., Subiah, N., Sharma, R., Gupta, S. S., Koul, P., \& Gupta, R. (2018). Block-4 Newborn and Child Health Care. In: IGNOU.

[41] Kwast, B. E. (1991). Postpartum haemorrhage: its contribution to maternal mortality. Midwifery, 7(2), 64-70.

[42] Lakeman, R. (2009). Suicide, Ethics and Service-user Participation in Mental Health: A Portfolio of Related Papers. James Cook University,

[43] Mack, N. (2005). Qualitative research methods: A data collector's field guide.

[44] Mahara, G., Barr, J., Thomas, J., Wang, W., \& Guo, X. (2016). Maternal health and its affecting factors in Nepal. Family Medicine and Community Health, 4(3), 30-34.

[45] Maswime, S., \& Buchmann, E. (2017). A systematic review of maternal near miss and mortality due to postpartum hemorrhage. International Journal of Gynecology \& Obstetrics, 137(1), 1-7.

[46] Montgomery, A. (2014). Pregnancy-related Deaths in India: Causes of Death and the Use of Health Services.

[47] Mousa, H. A., Blum, J., Abou El Senoun, G., Shakur, H., \& Alfirevic, Z. (2014). Treatment for primary postpartum haemorrhage. Cochrane Database Syst Rev, 2(2), CD003249.

[48] Muchemi, O. M., \& Gichogo, A. W. (2014). Maternal mortality in Central Province, Kenya, 20092010. The Pan African medical journal, 17.

[49] Mvundura, M., Kokonya, D., Abu-Haydar, E., Okoth, E., Herrick, T., Mukabi, J., . . . Burke, T. (2017). Cost-effectiveness of condom uterine balloon tamponade to control severe postpartum hemorrhage in Kenya. International Journal of Gynecology \& Obstetrics, 137(2), 185-191.

[50] Nadisauskiene, R. J., Kliucinskas, M., Dobozinskas, P., \& Kacerauskiene, J. (2014). The impact of postpartum haemorrhage management guidelines implemented in clinical practice: a systematic review of the literature. European Journal of Obstetrics \& Gynecology and Reproductive Biology, $178,21-26$.

[51] NASCOP. (2016). Guidelines on Use of Antiretroviral Drugs for Treating and Preventing HIV Infection in Kenya.

[52] NCAPD. (2010). Rapid assessment of partograph utilization in selected maternity units in Kenya. East African medical journal, 87(6), 235-241.

[53] Njuguna, J., Kamau, N., \& Muruka, C. (2017). Impact of free delivery policy on utilization of maternal health services in county referral hospitals in Kenya. BMC health services research, 17(1), 429. 
[54] Obare, F., Warren, C., Abuya, T., Askew, I., \& Bellows, B. (2014). Assessing the population-level impact of vouchers on access to health facility delivery for women in Kenya. Social science \& medicine, 102, 183-189.

[55] Ochako, R., Fotso, J.-C., Ikamari, L., \& Khasakhala, A. (2011). Utilization of maternal health services among young women in Kenya: insights from the Kenya Demographic and Health Survey, 2003. BMC pregnancy and childbirth, 11(1), 1.

[56] Ogan, C., Karakuş, T., \& Kurşun, E. (2013). Methodological issues in a survey of children's online risk-taking and other behaviours in Europe. Journal of Children and Media, 7(1), 133-150.

[57] The organization, W. H. (2016a). Strengthening Country Capacity on Maternal and Perinatal Death Surveillance and Response: Report of a South-East Asia Regional Meeting, 16-18 February 2016, Maldives. Retrieved from

[58] Organization, W. H. (2016b). World health statistics 2016: monitoring health for the SDGs sustainable development goals: World Health Organization.

[59] Organization, W. H., \& Unicef. (2012). Trends in maternal mortality: 1990 to 2010: WHO, UNICEF, UNFPA, and The World Bank estimates.

[60] Patil, A. V., Somasundaram, K., \& Goyal, R. (2002). Current health scenario in rural India. Australian Journal of Rural Health, 10(2), 129-135.

[61] Polit, D. F., \& Beck, C. T. (2008). Nursing research: Generating and assessing evidence for nursing practice: Lippincott Williams \& Wilkins.

[62] Prata, N., Bell, S., \& Weidert, K. (2013). Prevention of postpartum hemorrhage in low-resource settings: current perspectives. International journal of women's health, 5, 737.

[63] Prata, N., Passano, P., Sreenivas, A., \& Gerdts, C. E. (2010). Maternal mortality in developing countries: challenges in scaling-up priority interventions. Women's Health, 6(2), 311-327.

[64] Ramanathan, G., \& Arulkumaran, S. (2006). Postpartum hemorrhage. Journal of Obstetrics and Gynaecology Canada, 28(11), 967-973.

[65] Rosato, M., Laverack, G., Grabman, L. H., Tripathy, P., Nair, N., Mwansambo, C., . . . Perry, H. (2008). Community participation: lessons for maternal, newborn, and child health. The Lancet, 372(9642), 962-971.

[66] Senkubuge, F., Modisenyane, M., \& Bishaw, T. (2014). Strengthening health systems by health sector reforms. Global health action, 7(1), 23568.

[67] Shakur, H., Roberts, I., Fawole, B., Chaudhri, R., El-Sheikh, M., Akintan, A., . . Abdulkadir, A. (2017). Effect of early tranexamic acid administration on mortality, hysterectomy, and other morbidities in women with post-partum haemorrhage (WOMAN): an international, randomised, double-blind, placebo-controlled trial. The Lancet, 389(10084), 2105-2116.

[68] Smith, J. M., Currie, S., Cannon, T., Armbruster, D., \& Perri, J. (2014). Are national policies and programs for the prevention and management of postpartum hemorrhage and preeclampsia adequate? A key informant survey in 37 countries. Global Health: Science and Practice, 2(3), 275-284.

[69] Surbakti, P. (1995). Indonesia's National Socio-Economic Survey: a continual data source for analysis on welfare development: Central Bureau of Statistics.

[70] Saved, B. K., Pradhan, A., Barnett, S., Puri, M., Chitrakar, S. R., Poudel, P., . . Hulton, L. (2009). Nepal maternal mortality and morbidity study 2008/2009: summary of preliminary findings. Kathmandu, Nepal: Family Health Division, Department of Health Services, Ministry of Health, Government of Nepal.

[71] UNFPA, I. (2014). WHO: The state of the world's midwifery 2014: A universal pathway. A women's right to health. United Nations Population Fund, New York.

[72] UNICEF. (2011). A conceptual framework and research approach for identifying, analyzing and prioritizing barriers to effective maternal, newborn and child health interventions.

[73] UNICEF. (2012). UNFPA, The World Bank. Trends in maternal mortality: 1990 to 2010. World Health Organization, UNICEF, UNFPA, and The World Bank.

[74] Unicef. (2015). Trends in maternal mortality: 1990-2015: estimates from WHO, UNICEF, UNFPA, World Bank Group, and the United Nations Population Division. 
[75] White, D., Dynes, M., Rubardt, M., Sissoko, K., \& Stephenson, R. (2013). The influence of intrafamilial power on maternal health care in Mali: perspectives of women, men, and mothers-inlaw. International perspectives on sexual and reproductive health, 58-68.

[76] WHO. (2014a). Health for the world's adolescents: a second chance in the second decade: summary.

[77] WHO. (2014b). Postpartum haemorrhage management, risks, and maternal outcomes: findings from the World Health Organization Multicountry Survey on Maternal and Newborn Health. BJOG: An International Journal of Obstetrics \& Gynaecology, 121, 5-13.

[78] WHO. (2017). Global strategy for women's, children's and adolescents' health (2016-2030). Organization, 2016(9).

[79] WHO, U. (2015). UNFPA, World Bank Group, and the United Nations Population Division. Trends in maternal mortality: 1990 to 2015. Estimates by WHO, UNICEF. In: UNFPA, World Bank Group, and the United Nations Population Division. Geneva.

[80] Abbott, B. B., \& Bordens, K. S. (2011). Research design and methods: A process approach. In: New York: McGraw-Hill.

[81] Almeida, J. M., Eager, D. L., Vernon, M. K., \& Wright, S. J. (2004). Minimizing delivery cost in scalable streaming content distribution systems. IEEE Transactions on Multimedia, 6(2), 356-365.

[82] Asamoah, B. O., Moussa, K. M., Stafström, M., \& Musinguzi, G. (2011). Distribution of causes of maternal mortality among different socio-demographic groups in Ghana; a descriptive study. BMC public health, 11(1), 159.

[83] Banke-Thomas, A., Banke-Thomas, O., Kivuvani, M., \& Ameh, C. A. (2017). Maternal health services utilisation by Kenyan adolescent mothers: analysis of the Demographic Health Survey 2014. Sexual \& Reproductive Healthcare, 12, 37-46.

[84] Baqui, A. H., Ahmed, S., El Arifeen, S., Darmstadt, G. L., Rosecrans, A. M., Mannan, I., . . Seraji, H. R. (2009). Effect of timing of first postnatal care home visit on neonatal mortality in Bangladesh: a observational cohort study. Bmj, 339, b2826.

[85] Beck, U., \& Grande, E. (2010). Varieties of second modernity: The cosmopolitan turn in social and political theory and research. The British journal of sociology, 61(3), 409-443.

[86] Bhutta, Z. A., Das, J. K., Bahl, R., Lawn, J. E., Salam, R. A., Paul, V. K., . . Chou, V. B. (2014). Can available interventions end preventable deaths in mothers, newborn babies, and stillbirths, and at what cost? The Lancet, 384(9940), 347-370.

[87] Blencowe, H., Cousens, S., Chou, D., Oestergaard, M., Say, L., Moller, A.-B., . . Lawn, J. (2013). Born too soon: the global epidemiology of 15 million preterm births. Reproductive health, 10(1), S2.

[88] Borghi, J., Ensor, T., Neupane, B. D., \& Tiwari, S. (2006). Financial implications of skilled attendance at delivery in Nepal. Tropical Medicine \& International Health, 11(2), 228-237.

[89] Brenner, S., De Allegri, M., Gabrysch, S., Chinkhumba, J., Sarker, M., \& Muula, A. S. (2015). The quality of clinical maternal and neonatal healthcare-a strategy for identifying 'routine care signal functions'. PloS one, 10(4), e0123968.

[90] Callaghan, L., Winters, J., \& McGrath, L. Maternal, Infant and Child Nutrition and Nurture: Relational, Bio-cultural and Spatial Perspectives.

[91] Cameron, M., \& Robson, S. (2006). Vital statistics: an overview. A Textbook of Postpartum Hemorrhage in Resource Poor Countries: A Comprehensive Guide to Evaluation, Management and Surgical Intervention. 1st ed. Kirkmahoe, Dumfriesshire, UK: Sapiens Publishing, 17-34.

[92] Creswell, J. W., \& Creswell, J. D. (2017). Research design: Qualitative, quantitative, and mixed methods approaches: Sage publications.

[93] Dolan, G., Ter Kuile, F. O., Jacoutot, V., White, N., Luxemburger, C., Malankirii, L., . . Nosten, F. (1993). Bed nets for the prevention of malaria and anaemia in pregnancy. Transactions of the Royal Society of Tropical Medicine and Hygiene, 87(6), 620-626.

[94] Dolea, C., AbouZahr, C., \& Stein, C. (2003). Global burden of maternal hemorrhage in the year 2000. Retrieved from

[95] Duke, T., Yano, E., Hutchinson, A., Hwaihwanje, I., Aipit, J., Tovilu, M., . . Lagani, W. (2016). Large-scale data reporting of paediatric morbidity and mortality in developing countries: it can be done. Archives of disease in childhood, 101(4), 392-397. 
[96] Eleje, G. U., Ezugwu, E. C., Eke, A. C., Eleje, L. I., Ikechebelu, J. I., Afiadigwe, E. A., . . Ezeama, C. O. (2016). Diagnostic performance of placental alpha-microglobulin-1 test in women with prolonged pre-labour rupture of membranes. The Journal of Maternal-Fetal \& Neonatal Medicine, 29(8), 1291-1296.

[97] Elkhoudri, N., Amor, H., \& Baali, A. (2015). Self-reported postpartum morbidity: prevalence and determinants among women in Marrakesh, Morocco. Reproductive health, 12(1), 75.

[98] Ergo, A., Eichler, R., Koblinsky, M., \& Shah, N. (2011). Strengthening health systems to improve maternal, neonatal and child health outcomes: a framework. Washington, DC: US Agency for Development, Maternal and Child Health Integrated Program.

[99] Ezegwui, H., Onoh, R. C., Ikeako, L., Onyebuchi, A., Umeorah, J., Ezeonu, P., \& Ibekwe, P. (2013). Investigating maternal mortality in a public teaching hospital, Abakaliki, Ebonyi State, Nigeria. Annals of medical and health sciences research, 3(1), 75-80.

[100] Felarmine, M., Joachim, O., \& Agina, O. (2016). Facility factors influencing utilization of active management of third stage of labour among skilled birth attendants in Kiambu county, Kenya. The Pan African medical journal, 25(Suppl 2).

[101] Fortney, J. A., Susanti, I., Gadalla, S., Saleh, S., Feldblum, P. J., \& Potts, M. (1988). Maternal mortality in Indonesia and Egypt. International Journal of Gynecology \& Obstetrics, 26(1), 21-32.

[102] Graham, W. J., \& Campbell, O. M. (1992). Maternal health and the measurement trap. Social science \& medicine, 35(8), 967-977.

[103] Haftu, A., Hagos, H., \& Mehari, M.-A. (2018). Pregnant women adherence level to antenatal care visit and its effect on perinatal outcome among mothers in Tigray Public Health institutions, 2017: cohort study. BMC research notes, 11(1), 872.

[104] Hahn, E. D., \& Doh, J. P. (2006). Using Bayesian methods in strategy research: an extension of Hansenet al. Strategic Management Journal, 27(8), 783-798.

[105] Hailu, A., \& Kebede, D. (1994). High-risk pregnancies in urban and rural communities in central part of Ethiopia. East African medical journal, 71(10), 661-666.

[106] Health, U. D. o., \& Services, H. (2016). Agency for Healthcare Research and Quality (AHRQ). 2014. Primary Care Workforce Facts and Stats(3).

[107] Hesse-Biber, S. (2012). Feminist approaches to triangulation: Uncovering subjugated knowledge and fostering social change in mixed methods research. Journal of Mixed Methods Research, 6(2), 137 146.

[108] Kagema, F., Ricca, J., Rawlins, B., Rosen, H., Mukhwana, W., Lynam, P., . . Miheso, A. (2011). Quality of care for prevention and management of common maternal and newborn complications: findings from a National Health Facility Survey in Kenya - are services provided according to international standards. Baltimore: Jhpiego.

[109] Kane, C. (1992). CL Kane and MPA Fisher, Phys. Rev. B 46, 15233 (1992). Phys. Rev. B, 46, 15233.

[110] KDHS. (2015). 2014 KDHS key findings.

[111] Kinuthia, K., Stephenson, M., \& Maogoto, E. (2019). Management of postpartum hemorrhage in a rural hospital in Kenya: a best practice implementation project. JBI database of systematic reviews and implementation reports.

[112] Kitui, J., Lewis, S., \& Davey, G. (2013). Factors influencing place of delivery for women in Kenya: an analysis of the Kenya demographic and health survey, 2008/2009. BMC pregnancy and childbirth, 13(1), 40.

[113] Kiwuwa, M. S., \& Mufubenga, P. (2008). Use of antenatal care, maternity services, intermittent presumptive treatment and insecticide treated bed nets by pregnant women in Luwero district, Uganda. Malaria Journal, 7(1), 44.

[114] Kosińska-Kaczyńska, K., Szymusik, I., Bomba-Opoń, D., Olejek, A., Sławska, H., Zimmer, M., .. . Seremak-Mrozikiewicz, A. (2016). Perinatal outcome according to chorionicity in twins-a Polish multicenter study. Ginekologia polska, 87(5), 384-389.

[115] Kumar, R., Subiah, N., Sharma, R., Gupta, S. S., Koul, P., \& Gupta, R. (2018). Block-4 Newborn and Child Health Care. In: IGNOU. 
[116] Kwast, B. E. (1991). Postpartum haemorrhage: its contribution to maternal mortality. Midwifery, 7(2), 64-70.

[117] Lakeman, R. (2009). Suicide, Ethics and Service-user Participation in Mental Health: A Portfolio of Related Papers. James Cook University,

[118] Mahara, G., Barr, J., Thomas, J., Wang, W., \& Guo, X. (2016). Maternal health and its affecting factors in Nepal. Family Medicine and Community Health, 4(3), 30-34.

[119] Maswime, S., \& Buchmann, E. (2017). A systematic review of maternal near miss and mortality due to postpartum hemorrhage. International Journal of Gynecology \& Obstetrics, 137(1), 1-7.

[120] Montgomery, A. (2014). Pregnancy-related Deaths in India: Causes of Death and the Use of Health Services. Mousa, H. A., Blum, J., Abou El Senoun, G., Shakur, H., \& Alfirevic, Z. (2014). Treatment for primary postpartum haemorrhage. Cochrane Database Syst Rev, 2(2), CD003249.

[121] Mvundura, M., Kokonya, D., Abu-Haydar, E., Okoth, E., Herrick, T., Mukabi, J., . . . Burke, T. (2017). Cost-effectiveness of condom uterine balloon tamponade to control severe postpartum hemorrhage in Kenya. International Journal of Gynecology \& Obstetrics, 137(2), 185-191.

[122] Nadisauskiene, R. J., Kliucinskas, M., Dobozinskas, P., \& Kacerauskiene, J. (2014). The impact of postpartum haemorrhage management guidelines implemented in clinical practice: a systematic review of the literature. European Journal of Obstetrics \& Gynecology and Reproductive Biology, $178,21-26$.

[123] NASCOP. (2016). Guidelines on Use of Antiretroviral Drugs for Treating and Preventing HIV Infection in Kenya.

[124] NCAPD. (2010). Rapid assessment of partograph utilisation in selected maternity units in Kenya. East African medical journal, 87(6), 235-241.

[125] Njuguna, J., Kamau, N., \& Muruka, C. (2017). Impact of free delivery policy on utilization of maternal health services in county referral hospitals in Kenya. BMC health services research, 17(1), 429.

[126] Ochako, R., Fotso, J.-C., Ikamari, L., \& Khasakhala, A. (2011). Utilization of maternal health services among young women in Kenya: insights from the Kenya Demographic and Health Survey, 2003. BMC pregnancy and childbirth, 11(1), 1.

[127] Ogan, C., Karakuş, T., \& Kurşun, E. (2013). Methodological issues in a survey of children's online risk-taking and other behaviours in Europe. Journal of Children and Media, 7(1), 133-150.

[128] Organization, W. H., \& Unicef. (2012). Trends in maternal mortality: 1990 to 2010: WHO, UNICEF, UNFPA, and The World Bank estimates.

[129] Patil, A. V., Somasundaram, K., \& Goyal, R. (2002). Current health scenario in rural India. Australian Journal of Rural Health, 10(2), 129-135.

[130] Polit, D. F., \& Beck, C. T. (2008). Nursing research: Generating and assessing evidence for nursing practice: Lippincott Williams \& Wilkins.

[131] Prata, N., Bell, S., \& Weidert, K. (2013). Prevention of postpartum hemorrhage in low-resource settings: current perspectives. International journal of women's health, 5, 737.

[132] Prata, N., Ejembi, C., Fraser, A., Shittu, O., \& Minkler, M. (2012). Community mobilization to reduce postpartum hemorrhage in home births in northern Nigeria. Social science \& medicine, 74(8), $1288-1296$.

[133] Ramanathan, G., \& Arulkumaran, S. (2006). Postpartum hemorrhage. Journal of Obstetrics and Gynaecology Canada, 28(11), 967-973. 
[134] Remya, R. (2010). Effectiveness of nursing care on mothers with post partum haemorrhage. Adhiparasakthi College of Nursing, Melmaruvathur,

[135] Rosato, M., Laverack, G., Grabman, L. H., Tripathy, P., Nair, N., Mwansambo, C., . . . Perry, H. (2008). Community participation: lessons for maternal, newborn, and child health. The Lancet, 372(9642), 962-971.

[136] Senkubuge, F., Modisenyane, M., \& Bishaw, T. (2014). Strengthening health systems by health sector reforms. Global health action, 7(1), 23568.

[137] Shakur, H., Roberts, I., Fawole, B., Chaudhri, R., El-Sheikh, M., Akintan, A., . . Abdulkadir, A. (2017). Effect of early tranexamic acid administration on mortality, hysterectomy, and other morbidities in women with post-partum haemorrhage (WOMAN): an international, randomised, double-blind, placebo-controlled trial. The Lancet, 389(10084), 2105-2116.

[138] Smith, J. M., Currie, S., Cannon, T., Armbruster, D., \& Perri, J. (2014). Are national policies and programs for the prevention and management of postpartum hemorrhage and preeclampsia adequate? A key informant survey in 37 countries. Global Health: Science and Practice, 2(3), 275-284.

[139] Saved, B. K., Pradhan, A., Barnett, S., Puri, M., Chitrakar, S. R., Poudel, P., . . Hulton, L. (2009). Nepal maternal mortality and morbidity study 2008/2009: summary of preliminary findings. Kathmandu, Nepal: Family Health Division, Department of Health Services, Ministry of Health, Government of Nepal.

[140] UNFPA, I. (2014). WHO: The state of the world's midwifery 2014: A universal pathway. A women's right to health. United Nations Population Fund, New York.

[141] UNICEF. (2011). A conceptual framework and research approach for identifying, analyzing and prioritizing barriers to effective maternal, newborn and child health interventions.

[142] UNICEF. (2012). UNFPA, The World Bank. Trends in maternal mortality: 1990 to 2010. World Health Organization, UNICEF, UNFPA, and The World Bank.

[143] White, D., Dynes, M., Rubardt, M., Sissoko, K., \& Stephenson, R. (2013). The influence of intrafamilial power on maternal health care in Mali: perspectives of women, men, and mothers-inlaw. International perspectives on sexual and reproductive health, 58-68.

[144] WHO. (2010).Monitoring the building blocks of a health system

[145] WHO. (2014a). Health for the world's adolescents: a second chance in the second decade: summary.

[146] WHO. (2014b). Postpartum hemorrhage management, risks, and maternal outcomes: findings from the World Health Organization Multicountry Survey on Maternal and Newborn Health. BJOG: An International Journal of Obstetrics \& Gynaecology, 121, 5-13.

[147] WHO. (2017). Global strategy for women's, children's and adolescents' health (2016-2030). Organization, 2016(9).

[148] WHO, U. (2015). UNFPA, World Bank Group, and the United Nations Population Division. Trends in maternal mortality: 1990 to 2015. Estimates by WHO, UNICEF. In: UNFPA, World Bank Group, and the United Nations Population Division. Geneva.

[149] WHO.(2020): Universal Health Coverage

[150] Ziyo, F. Y., Matly, F. A., Mehemd, G. M., \& Dofany, E. M. (2009). The relation between prenatal care and pregnancy outcome at Benghazi. Sudanese Journal of public health, 4(4), 403-410. 
